\title{
SEISMIC RISK ASSESSMENT AND MITIGATION AT EMERGENCY LIMIT CONDITION OF HISTORICAL BUILDINGS ALONG STRATEGIC URBAN ROADWAYS. APPLICATION TO THE "ANTIGA ESQUERRA DE L'EIXAMPLE" NEIGHBOURHOOD OF BARCELONA
}

\author{
Selma Cara ${ }^{1}$, Alessandra Aprile ${ }^{1}$ Luca Pelà $^{2 *}$ and Pere Roca ${ }^{2}$ \\ ${ }^{1}$ Department of Engineering, University of Ferrara, Via Saragat 1, 44122 Ferrara, Italy \\ e-mail: \{selma.cara; alessandra.aprile\}@unife.it \\ ${ }^{2}$ Department of Civil and Environmental Engineering, Universitat Politècnica de Catalunya (UPC- \\ BarcelonaTech), Jordi Girona 1-3, 08034 Barcelona, Spain \\ e-mail: \{luca.pela; pere.roca.fabregat\}@upc.edu
}

\begin{abstract}
This paper presents a management tool for the large-scale assessment and mitigation of the seismic risk of urban systems. The research introduces a new perspective for a scientifically tackled holistic approach. The proposed methodology considers multiple objectives, from the identification of the most vulnerable buildings whose collapse may hinder the operationality of strategic urban roadways after the occurrence of an earthquake, up to the proposal of proper interventions to improve their functionality. The approach uses a performance-based approach founded on the concept of urban Emergency Limit Condition. Plotting maps of geo-referenced scenarios by means of GIS software have revealed to be extremely useful to detect the weak points of the urban network and to plan suitable strategies of seismic risk mitigation and appropriate enhancement of reliability. The proposed methodology is applied to the "Antiga Esquerra de l'Eixample" neighbourhood of Barcelona that hosts the strategic route to the hospital and is characterized by high levels of seismic vulnerability of existing buildings and exposition of its highdensity population.
\end{abstract}

KEYWORDS: seismic risk, risk assessment, performance based urban assessment, emergency limit state, urban resilience, risk mitigation, risk reduction policies, built heritage protection, GIS.

${ }^{*}$ Corresponding author 


\section{INTRODUCTION}

Effects caused by natural disasters may turn out to be so devastating to disable entire territories. The worldwide balance of damage reported every year due to earthquakes is dramatic. Even a seismic event of low intensity may produce heavy impact on historical cities, causing delay in the emergency response and lifelines inoperability. Consequences of earthquake-induced disasters on urban areas can be substantially reduced by promoting efficient public policies of risk mitigation and by developing proper emergency plans. The development of prediction models addressed to seismic risk mitigation of urban systems is definitely needed to prevent, or at least to limit, strong economic, social and cultural losses. The fundamental challenge of this task is the assurance of structural safety in a sustainable built environment, aimed to the preservation of the local culture and the collective memory. For that purpose, urban centres continuously require maintenance and rehabilitation, as well as proper financial sources for their preservation.

The risk to any catastrophic event is defined as the probability of a system to reach a prefixed level of loss in a certain time interval. This loss is identified as the cost that should be supported to return the damaged system to the previous condition (Coburn and Spence 2002). The risk assessment of a given area is related to the evaluation of three fundamental variables, i.e. hazard, vulnerability, and exposure (Crichton 1999, Cardona et al. 2012). Hazard can be defined as the probability of occurrence of a seismic event of certain intensity in a specific site, and it mainly depends on the geographical location and the geological characteristics of the site where the event is expected. Vulnerability can be defined as the intrinsic potential of buildings to suffer a certain level of damage when subjected to a seismic event of defined intensity. Such level of damage may bring immediate decline to the building's functionality and, even worst, may lead to its permanent unserviceability. Finally, exposure is related to the nature, the quantity and the value of properties and activities of the area that can be influenced directly or indirectly by a seismic event. The seismic risk of a complex urban system can be mitigated by only reducing its vulnerability, since it is not generally possible to intervene on hazard and exposure. The most common approach nowadays to mitigate the seismic risk consists in reducing single buildings' vulnerabilities through ad-hoc structural interventions. However, buildings usually do not constitute independent units and do not have independent structural behavior due to the complex development of the urban mesh. For this reason, the current research focus needs to be relocated from the analysis of the single buildings to that of the overall urban system, by considering proper relationships among buildings, roads, lifelines, and definitely by extending the research to a larger scale (Tilio et al. 2011, Lynch 2004), see Figure 1. 


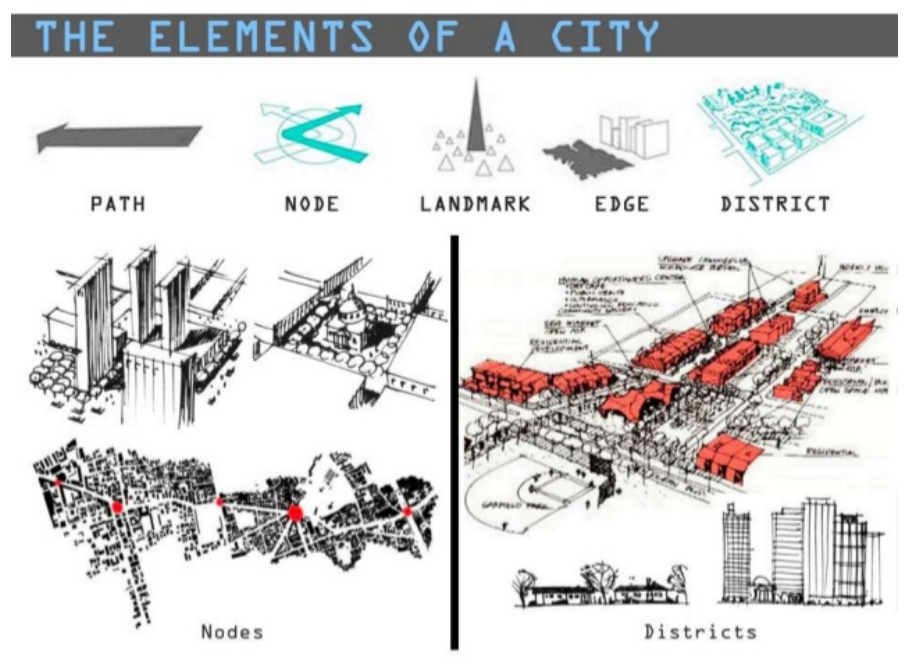

Figure 1. Constituent elements of a city and relationship among them (Lynch 2004).

It is not a simple task to identify the most vulnerable urban buildings, as well as to understand to which extent to intervene on them to achieve the needed system's overall upgrading with the limited available resources. Public authorities need simple yet effective models prior to carry out cost-benefit analyses to optimize the time and costs necessary for interventions. Required models must predict the effects of a seismic event of a given intensity on the urban site, allow the simulation of mitigation measures to reduce the system's vulnerability and finally re-evaluate the overall effects on the improved system. By performing iteratively such evaluations, public authorities can identify the optimal interventions that produce the greatest risk reduction with the minimum economic impact. Possible measures of mitigation concern not only structural strengthening, but also territorial planning and, more generally, the targeted development of a "smart city" able to guarantee the security and welfare of inhabitants (Paskaleva 2009). All the aforementioned models have to deal with a large number of input variables, including information about buildings, routes, lifelines, historic earthquakes' data, soil condition, etc. These required models are thus inevitably complex and costly from the computational point of view. All the necessary information has to be collected in huge databases with the possibility to be updated over time. The data collection stage is particularly critical, as it must be accurate but also sufficiently expeditious to reduce the processing time. To date, data collection and building survey is still too slow and not free of obstacles, so further research is needed to improve the available strategies (Jiménez et al. 2018).

Seismic risk mitigation is a straight way to increase urban resilience, defined as the capacity of a system to adapt itself to new, generally negative, scenarios, in order to re-establish its normal original conditions. 
The International Strategy for Disaster Reduction of the United Nations (ISDR 2015) defines resilience as the capacity of a system, community or society potentially exposed to hazards to adapt to a new scenario by resisting or changing, in order to reach and maintain an acceptable level of functioning and structure. Resilience is determined by a social system capable of organizing itself to increase its capacity of learning from past disasters for its future protection, as well as to improve risk reduction measures. This can be achieved by working on structural aspects, emergency response and strategies, and involving institutions and organizations with emphasis on those related to essential functions for community's wellbeing. Every city can express a certain level of resilience, and the identification of its most influent elements is strategic in order to detect intervention criteria aimed to its improvement (Burton et al. 2016). Numerous methodologies for the seismic vulnerability assessment of existing buildings were developed in the last 30 years (Calvi et al. 2006). Different methods of assessment, with different levels or accuracy, are currently available in the scientific literature. Analytical methods, also known as direct methods, require sophisticated structural analyses, e.g. by using the Finite Element Method, to assess the seismic capacity of the buildings. These methods are very accurate but expensive due to the large amount of input data and the working time necessary for the analyses. Empirical methods, also known as indirect methods, are less accurate but more affordable for large urban assessments since they are based on the definition of damage probability matrices and vulnerability functions from in-situ observation of the seismic damage after past major earthquakes (GNDT 1986, 1993, 1999; CETE Méditerranée 2008). These methodologies may be seen as the first level of a multilevel approach aimed at identifying those urban buildings requiring further detailed analyses within a cost- and time-effective conceptual framework. Several indirect methodologies combine the vulnerability index method by Benedetti and Petrini (1984) with the European Macroseismic Scale definition (EMS-98) by Grünthal et al. 1998. The RISK-UE project (Mouroux et al. 2004) proposed two approaches for the vulnerability assessment of buildings, i.e. a macroseismic method based on macroseismic intensity hazard maps and a mechanical model based on the definition of the seismic hazard by peak ground accelerations and spectral values (Giovinazzi and Lagomarsino 2004, Lagomarsino and Giovinazzi 2006, Bernardini et al. 2007).

More recent studies focused on the possibility to carry out seismic vulnerability assessments quickly and with limited costs, in order to extend the application to entire urban systems (Formisano et al. 2011, 2015). The proposed methodologies were applied to complex case studies, such as the historical centre of Izmir in Turkey (Korkmaz et al. 2010), Chania in Greece (Sarris et al. 2010), Barcelona in Spain (Lantada et al. 2010), L’Aquila (D'Ayala and Paganoni 2011) and Foggia (Uva et al. 2016) in Italy, Bucharest in Romania (Armaş 2012), Coimbra (Vicente et al. 2011) and Seixal (Ferreira et al. 2013) in 
Portugal. Several research projects assess urban seismic vulnerability also including social costs and human losses, e.g. the works developed in Annaba (Athmani et al. 2015) and Algiers (Novelli et al. 2015) in Algeria, Faro (Maio et al. 2016) and Horta (Ferreira et al. 2017) in Portugal, and Cairo in Egypt (Badawy et al. 2017).

New methodological approaches for the urban risk assessment were recently developed thanks to the emergency management work operated by civil protection agencies and, more generally, by organizations dedicated to infrastructures' territorial management. In this context, considerable interest is paid to the Emergency Limit Condition (ELC) of an urban system after an earthquake. This is defined as the condition of retaining the efficiency of the functions that are strategic for the emergency operations, the accessibility and the connection of the territorial context after an earthquake (Bramerini et al. 2014). If the ELC condition is not guaranteed, physical and functional damages occur that can conduct to the interruption of almost the totality of the urban functions, with very harsh implications for the whole community. Starting from the ELC definition, a more general performance-based approach was proposed for the probabilistic evaluation of damage, seismic assessment and resilience of urban systems with reference to different performance levels (Lagomarsino and Cattari 2015, Burton et al. 2016). An operative performance-based methodology for urban seismic risk assessment was proposed very recently by Staniscia et al. (2017). The proposed approach opens to new perspectives by extending the concept of ELC with the definition of higher performance levels for the urban system, corresponding to potentially higher levels of resilience. The concept of Minimum Urban Structure (MUS) is defined in order to consider different urban sub-systems for different performance levels. The MUS represents the minimum part of the urban system that must be efficiently protected from an earthquake in order to guarantee a fast recovery of the normal conditions. The MUS constitutes somehow a vital organ of the city, and must be preserved in order to confer resilience to the entire urban system (Burton et al. 2016). MUS can include buildings, roads, open spaces and lifelines, such as water and gas pipelines, electricity and ICT networks. Basaglia et al. $(2016,2018)$ proposed a new methodology by applying probabilistic mechanical models to assess different MUS performance levels, evaluating the urban system reliability as a function of the attended seismic intensity. The proposed methodology was validated based on postseism real data survey of Concordia sulla Secchia, Italy, hit by the Pianura Padana earthquake in 2012. Following the aforementioned researches, this paper presents a novel contribution for the assessment and mitigation of the seismic risk at ELC of urban systems. The main novelty of the study relies in the proposal of a simplified model to investigate the influence of the collapse of interfering buildings on the operationality of strategic urban roadways, as well as the possible actions that may lead to improve their 
functionality after the occurrence of an earthquake. The proposed model is based on a quick evaluation of the seismic risk of interfering buildings by using the vulnerability index theoretical framework (Benedetti and Petrini 1984). This key choice enables the application of the model to large-scale urban assessments, as a simple approach preparatory to further detailed analyses and ad-hoc interventions on critical urban buildings. The purpose is obtaining helpful indicators for urban planning to optimize time and resources in large scale seismic risk mitigation policies.

The first stage of the proposed methodology consists in the identification of interfering buildings whose damage or collapse may affect the functionality of vital connections during the post-seism emergency. The damage grade of the chosen buildings, corresponding to the expected macro-seismic intensity in the city, is evaluated after having determined the vulnerability indexes by using the GDNT method (1986, 1993, 1999). Proper analytical functions are adopted to derive the macro-seismic vulnerability from the GNDT vulnerability indexes, making a clear distinction between masonry and reinforced concrete structures (Ferreira et al. 2013, Basaglia et al. 2018). The directional character of the seismic vulnerability of the buildings is explicitly taken into account within the vulnerability index method by using a novel elliptic interpolation (Basaglia et al. 2016). The functional relationship at ELC among the interfering buildings is expressed by a proper mechanical model whose definition allows the evaluation of the reliability of the urban system crossed by the strategic roadway. The use of a Geographic Information System (GIS) leads to the construction of georeferenced maps for the simulation of post-earthquake scenarios. The GIS tool reveals to be also necessary to identify readily the buildings within the urban network presenting highest seismic risk and thus requiring further detailed analysis and retrofit if necessary. These outcomes are extremely important for public safety or civil protection agencies to assess the impact of possible intervention strategies, as well as to optimize the management of the seismic emergency.

The proposed methodology is applied to the "Antiga Esquerra de l'Eixample" neighbourhood of Barcelona that hosts the strategic roadway to the existing hospital. From this special case study, possible retrofit interventions are hypothesized for structural reinforcement to assess the feasibility of the seismic risk mitigation measures on the interfering buildings. 


\section{SEISMIC RISK ASSESSMENT AND MITIGATION AT URBAN EMERGENCY LIMIT CONDITION (ELC)}

\subsection{Seismic vulnerability and damage assessment}

The Vulnerability index method proposed by the Italian research institution Gruppo Nazionale per la Difesa dai Terremoti (GNDT 1986, 1993, 1999), based on the previous studies by Benedetti and Petrini (1984), has been widely used during the last decades. This methodology establishes a relationship between the seismic action intensity and the expected damage on a structure through the definition of a vulnerability index. This variable is an empirical function of the following eleven different parameters describing the overall structural vulnerability: type and organization of the resisting system; quality of the resisting system; conventional strength; building position and foundations; horizontal diaphragms; plan configuration; configuration in elevation; maximum distance between walls for masonry structures or connections and critical members for reinforced concrete (RC) structures; roof (for masonry structures) or low ductility elements (for RC structures); non-structural elements; current condition. Masonry and RC structures present four classes of vulnerability, from A to D, being A the least vulnerable class.

Following the forms proposed by GNDT, the vulnerability index is estimated by assigning class scores $C_{v i}$ and weights $w_{i}$ to the structural parameters referring to the structural features of the single building, according to the following relationship:

$$
I_{V}^{*}=\sum_{i=1}^{N} C_{v i} \cdot w_{i}
$$

being $N=11$ in the GNDT proposal. Class scores $C_{v i}$ and weights $w_{i}$ are different for masonry and RC buildings, for more details see Tables 1-2 (CETE Méditerranée 2008). The weight of all the parameters is equal 1.0 for RC buildings, whereas for masonry buildings it ranges between 0.25 and 1.5, being the "conventional strength" the parameter with maximum weight. A normalized vulnerability index $I_{V}$ is used in practical applications, varying within the range $0 \leq I_{V} \leq 100$. The minimum value $I_{V}=0$ indicates no seismic vulnerability, whereas the maximum value $I_{V}=100$ denotes the maximum

vulnerability. The determination of the normalized vulnerability index $I_{V}$ is straightforward for masonry buildings, starting from the value of the vulnerability index $I_{V}^{*}$ of Equation (1). The following expressions are used instead to normalize the vulnerability index of RC buildings: 


$$
\begin{aligned}
\text { If } I_{V}^{*}>-6.5 & \rightarrow I_{V}=-10.07 \cdot I_{V}^{*}+2.5175 \\
\text { If } I_{V}^{*}<-6.5 & \rightarrow I_{V}=-1.731 \cdot I_{V}^{*}+56.72
\end{aligned}
$$

\begin{tabular}{|c|c|c|c|c|c|c|}
\hline & \multirow[t]{2}{*}{ Parameter } & \multicolumn{4}{|c|}{ Class $C_{\mathrm{vi}}$} & \multirow[t]{2}{*}{ Weight $w_{\mathrm{i}}$} \\
\hline & & A & $\mathrm{B}$ & $\mathrm{C}$ & $\mathrm{D}$ & \\
\hline P1 & Type and organization of the resisting system & 0 & 5 & 20 & 45 & 1.00 \\
\hline P2 & Quality of the resisting system & 0 & 5 & 25 & 45 & 0.25 \\
\hline P3 & Conventional strength & 0 & 5 & 25 & 45 & 1.50 \\
\hline P4 & Building position and foundations & 0 & 5 & 15 & 45 & 0.75 \\
\hline P5 & Horizontal diaphragms & 0 & 5 & 25 & 45 & variable* \\
\hline P6 & Plan configuration & 0 & 5 & 25 & 45 & 0.50 \\
\hline P7 & Configuration in elevation & 0 & 5 & 25 & 45 & variable* \\
\hline P8 & Maximum distance between walls & 0 & 5 & 25 & 45 & 0.25 \\
\hline P9 & Roof & 0 & 15 & 25 & 45 & variable* \\
\hline $\mathrm{P} 10$ & Non-structural elements & 0 & 0 & 25 & 45 & 0.25 \\
\hline P11 & Current condition & 0 & 5 & 25 & 45 & 1.00 \\
\hline
\end{tabular}

Table 1. Vulnerability index parameters assumed for masonry buildings: class scores and weights.

* see CETE Méditerranée (2008)

Table 2. Vulnerability index parameters assumed for reinforced concrete buildings: class scores and weights.

\begin{tabular}{ccccccc}
\hline & Parameter & \multicolumn{3}{c}{ Class $C_{\mathbf{v i}}$} & \multirow{2}{*}{ Weight $w_{\mathbf{i}}$} \\
\cline { 3 - 6 } & & $\mathrm{A}$ & $\mathrm{B}$ & $\mathrm{C}$ & $\mathrm{D}$ & \\
\hline P1 & Type and organization of the resisting system & 0 & -1.00 & -2.00 & 0 & 1.00 \\
\hline P2 & Quality of the resisting system & 0 & -0.25 & -0.50 & 0 & 1.00 \\
\hline P3 & Conventional strength & 0.25 & 0 & -0.25 & 0 & 1.00 \\
\hline P4 & Building position and foundations & 0 & -0.25 & -0.50 & 0 & 1.00 \\
\hline P5 & Horizontal diaphragms & 0 & -0.25 & -0.50 & 0 & 1.00 \\
\hline P6 & Plan configuration & 0 & -0.25 & -0.50 & 0 & 1.00 \\
\hline P7 & Configuration in elevation & 0 & -0.50 & -1.50 & 0 & 1.00 \\
\hline P8 & Connections and critical elements & 0 & -0.25 & -0.50 & 0 & 1.00 \\
\hline P9 & Low ductility elements & 0 & -0.25 & -0.50 & 0 & 1.00 \\
\hline P10 & Non-structural elements & 0 & -0.25 & -0.50 & 0 & 1.00 \\
\hline
\end{tabular}


The GNDT methodology was originally developed for isolated buildings and the aforementioned eleven parameters actually refer to each specific building's structural characteristics. However, historical centres normally present buildings organized in aggregates within the urban mesh (Figure 2). Adjacent buildings within aggregates may interact under the effect of seismic actions and this effect shall be considered in the computation of the vulnerability index. The effect of the buildings' aggregates is taken into account in this study by following the approach proposed by Formisano et al. $(2011,2015)$ and later refined by Basaglia et al. (2016). The basic idea is adding five additional parameters to the original formulation by GNDT (thus $N=16$ in Equation 1), in order to describe the interaction between adjacent buildings due to their diversities in plan and in elevation, presence of staggered floors, structural or typological heterogeneity, and different percentage of openings among adjacent facades. Formisano et al. calibrated the scores and weights after developing parametric numerical analyses of a typical masonry aggregate in Campania (Italy), whereas Basaglia et al. recalibrated the same parameters based on survey data from recent Italian earthquakes. Table 3 presents the adopted class scores and weights for the evaluation of the vulnerability index of masonry and RC buildings in urban aggregates.

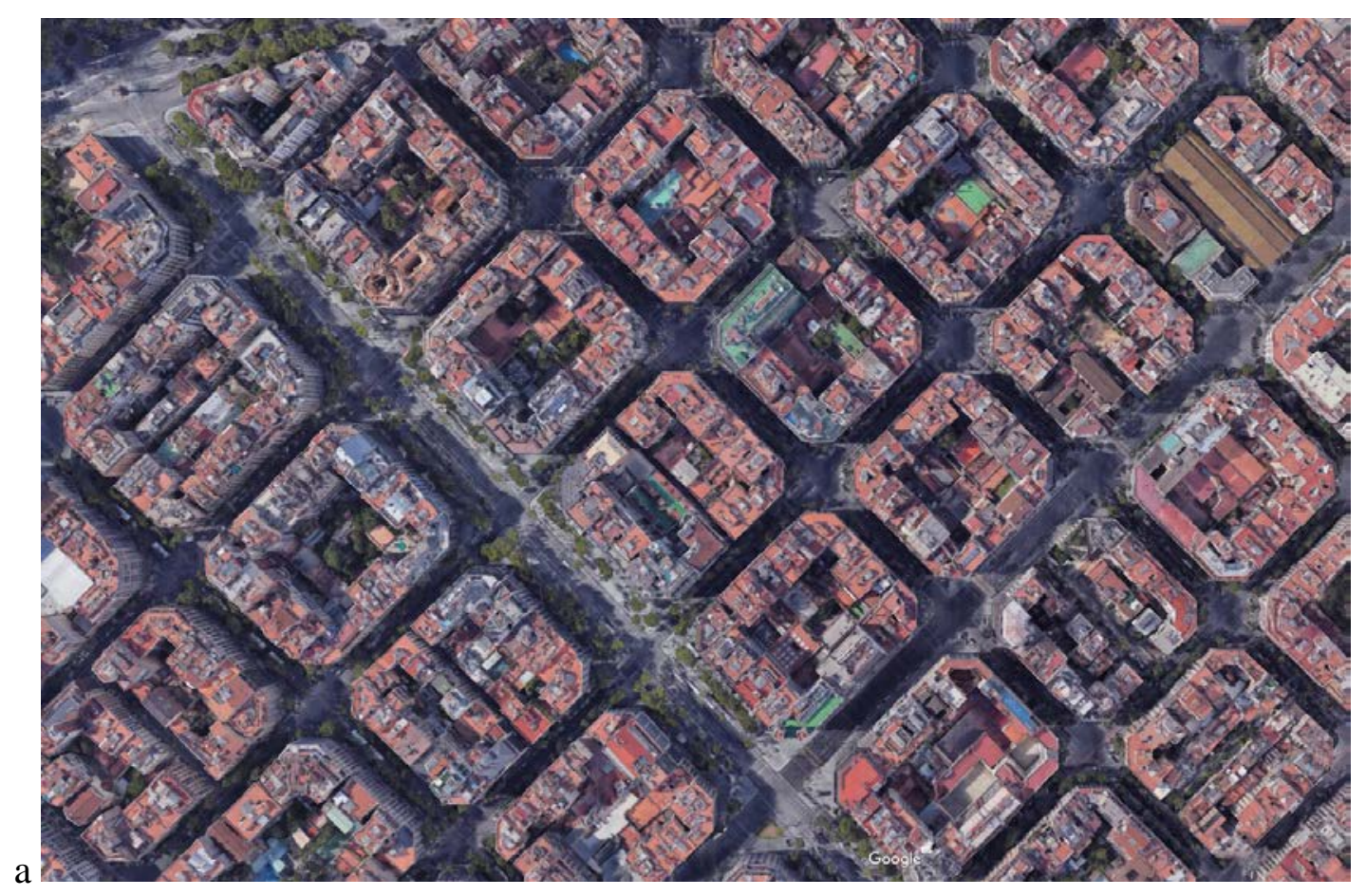




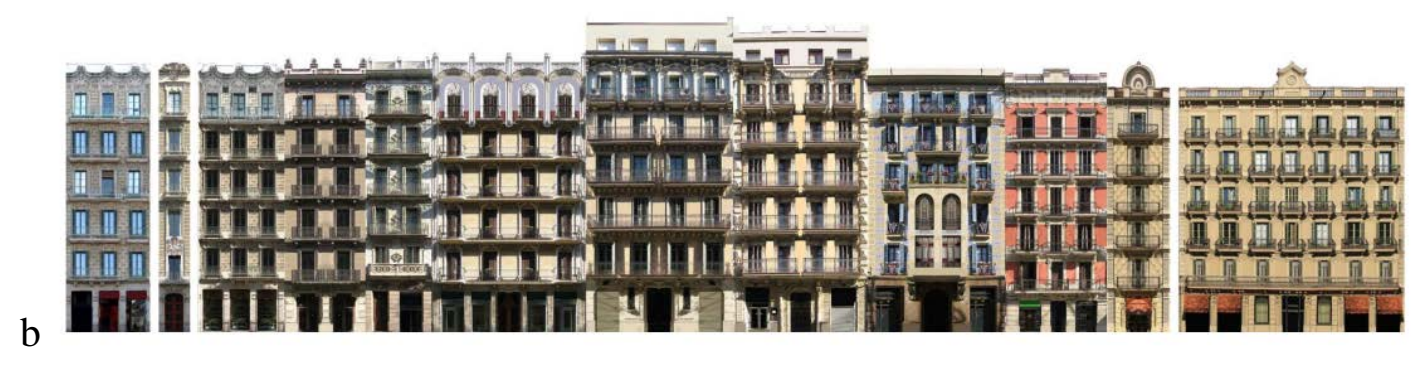

Figure 2. Example of urban mesh from the Eixample district of Barcelona: (a) view of building blocks (source: Google Maps) and (b) façades of aggregate buildings (Castilla Marne, 2010)

Table 3. Vulnerability index parameters assumed for buildings in aggregates: class scores and weights.

\begin{tabular}{lcccccc}
\hline & Parameter & \multicolumn{4}{c}{ Class $\boldsymbol{C}_{\mathbf{v i}}$} & \multirow{2}{*}{ Weight $\boldsymbol{w}_{\mathbf{i}}$} \\
\cline { 3 - 6 } & A & $\mathrm{B}$ & $\mathrm{C}$ & $\mathrm{D}$ & \\
\hline P12 & Interaction in elevation & 0 & 15 & 25 & 45 & 1.25 \\
\hline P13 & Floor plans' interaction & 0 & 5 & 15 & 45 & 1.75 \\
\hline P14 & Presence of staggered floors & 0 & 25 & 35 & 45 & 0.75 \\
\hline P15 & Structural or typological heterogeneity & 0 & 10 & 20 & 45 & 1.50 \\
\hline P16 & $\begin{array}{c}\text { Percentage difference of openings } \\
\text { among adjacent facades }\end{array}$ & 0 & 15 & 35 & 45 & 1.25 \\
\hline
\end{tabular}

Urban buildings have usually irregular shapes and present different structural configurations along their principal directions. Structural strength and stiffness, as well as the boundary conditions, could be different along the different principal directions of the building. For this reason, it is very important to evaluate distinct vulnerability indexes along the different principal directions of each building. The principal directions of the buildings can also be differently oriented within the mesh of urban blocks. Geographic orientation of the different buildings is driven by the historical development of the city, which can be ruled by local geographic elements (soil orography, waterways, coastal proximity) and socio-economic elements (main roadways, productive areas, etc.). A novel method to evaluate the directionality of the seismic vulnerability index was proposed by Basaglia et al. (2016) following a previous work by Grimaz (1993). The method considers an elliptic function to describe the plan variability of the vulnerability index. The elliptic vulnerability concept is also adopted in the present study, in order to evaluate the directional effect of the earthquake on the urban buildings' vulnerability. Once the vulnerability indexes $I_{V x}$ and $I_{V y}$ are evaluated along the building's principal directions $x$ and 
$y$, the vulnerability index $I_{V \alpha}$ along a generic direction of the earthquake $\alpha$ is derived from the following expression:

$$
I_{V \alpha}=\sqrt{I_{V x}{ }^{2}[\cos (\alpha-\theta)]^{2}+I_{V y}{ }^{2}[\sin (\alpha-\theta)]^{2}}
$$

being $\theta$ the angle of inclination of the $x$ principal direction of the building. Both angles $\alpha$ and $\theta$ are measured anticlockwise with respect to East-West cardinal axis.

The directionality of the seismic vulnerability is taken into account by applying separately the vulnerability index method along the two different principal directions of the building $x$ and $y$. For the case of masonry and RC buildings, two separate scores for the P3 parameter "Conventional strength" are calculated by accounting for the different resisting areas of the vertical structural members (walls and columns) along $x$ and $y$ directions. These two different scores produce different vulnerability indexes $I_{V x}$ and $I_{V y}$. Equation (3) allows to extrapolate the vulnerability index $I_{V \alpha}$ for all the possible directions $\alpha$ of the earthquake, given the orientation $\theta$ of the building within the urban network.

According to the GNDT approach, and taking into account Equation (3), the macro-seismic vulnerability parameter $V_{\alpha}$ in the earthquake incidence direction $\alpha$ is expressed by empirically-based analytical correlations, depending on the structural typology. The expression suggested by Ferreira et al. (2013) is implemented for unreinforced masonry buildings:

$$
V_{\alpha}=0.592+0.0057 \cdot I_{V \alpha}
$$

The expression suggested by Basaglia et al. (2018) is used for RC buildings:

$$
V_{\alpha}=0.24+0.0165 \cdot I_{V \alpha}-0.00003333 \cdot I_{V \alpha}^{2}
$$

An earthquake with incidence direction $\alpha$ will induce, based on its intensity, a certain amount of damage to the building with vulnerability $V_{\alpha}$ along the same direction. This work refers to the five non-null discrete damage grades coincident to the damage scale adopted by the EMS-98 macroseismic scale (Grunthal 1998): slight $\left(D_{1}\right)$, moderate $\left(D_{2}\right)$, heavy $\left(D_{3}\right)$, very heavy $\left(D_{4}\right)$ and destruction $\left(D_{5}\right)$. If we considered the histogram of the damage grades observed on a sample of buildings struck by the earthquake, it would be possible to define the mean damage grade $\mu_{D}$ as the mean value (barycentre abscissa) of the discrete damage distribution:

$$
\mu_{D}=\sum_{k=0}^{5} p_{k} k
$$


where $p_{k}$ is the probability of having a specific damage grade $D_{k}$ in the sample of buildings.

The mean damage grade is a continuous parameter representing the distribution of damage to the investigated set of buildings. The representative range of the mean damage grade is $0 \leq \mu_{D} \leq 5$ following the EMS-98 approach. Lagomarsino and Giovinazzi (2006) and Bernardini et al. (2007) proposed semi-empirical expressions for the evaluation of the building's mean damage grade as a function of its vulnerability and the macro-seismic intensity $I_{E M S-98}$, with $0 \leq I_{E M S-98} \leq 12$ (Grünthal et al. 1998). Their equations are rearranged in this work in order to take into account both the effects of vulnerability and directionality of earthquake on the mean damage grade value:

$$
\mu_{D}=2.5\left[1+\tanh \left(\frac{I_{E M S-98}+6.25 \cdot V_{\alpha}-13.1}{Q}\right)\right] \cdot f\left(I_{E M S-98}, V_{\alpha}\right)
$$

where $f\left(I_{E M S-98}, V_{\alpha}\right)$ is a function depending of the vulnerability index and macro-seismic intensity, introduced to understand the trend of the numerical vulnerability curves taken from the EMS-98 for the lower extremes of the intensity grades, as proposed by Bernardini et al. (2007):

$$
f\left(I_{E M S-98}, V_{\alpha}\right)=\left\{\begin{array}{cc}
e^{\frac{V_{\alpha}}{2} \cdot\left(I_{E M S-98}-7\right)} & I_{E M S-98} \leq 7 \\
1 & I_{E M S-98}>7
\end{array}\right.
$$

Parameter $Q$ is the ductility index that is correlated to structural ductility and determines the rate of increase of the damage with macro-seismic intensity. Lagomarsino and Giovinazzi (2006) provided representative values for this parameter based on structural typology, e.g. $Q=2.3$ for unreinforced masonry buildings and $Q=2.3 \div 3.3$ for RC buildings.

The Damage Probability Matrices (DPMs) are then used to evaluate the probabilities of occurrence of a given damage grade for a given macro-seismic intensity and vulnerability. This works considers a continuous probability Beta distribution with the following Probability Density Function (PDF) and Cumulative Density Function (CDF):

$$
\begin{gathered}
P D F: \quad p_{\beta}(x)=\frac{\Gamma(t)}{\Gamma(r) \Gamma(t-r)} \frac{(x-a)^{r-1}(b-x)^{t-r-1}}{(b-a)^{t-1}} \quad a \leq x \leq b \\
C D F: \quad P_{\beta}(x)=\int_{a}^{x} p_{\beta}(y) d y
\end{gathered}
$$

where $a, b, t$, and $r$ are the parameters of the distribution, $x$ is the independent variable which can range between values $a$ and $b$, and $\Gamma$ is the gamma function. Parameters $t$ and $r$ control the shape of the Beta distribution, since they relate to the mean $\mu_{x}$ and variance $\sigma_{x}{ }^{2}$ as follows: 


$$
\begin{gathered}
t=\frac{\mu_{x}\left(a+b-\mu_{x}\right)-a b}{\sigma_{x}^{2}}-1 \\
r=t \frac{\mu_{x}-a}{b-a}
\end{gathered}
$$

The parameter $t$ is assumed equal to 8 to represent the variance of the possible damage distributions (Bernardini et al. 2007), and then $r$ is calculated by using Equation (12). The values of $a$ and $b$ are 0 and 6 respectively by making reference to the following definition of the probability associated to each damage grade $D_{k}$ with $k=0 \div 5$ (Giovinazzi 2005):

$$
p_{k}=\int_{k}^{k+1} p_{\beta}(y) d y=P_{\beta}(k+1)-P_{\beta}(k)
$$

\subsection{ELC definition}

The next step of the methodology consists in the proper definition of the ELC for the analysed urban context. The ELC system is composed of buildings, roads and open areas able to guarantee strategic functions during the emergency, see for instance Figure 3 (Bramerini et al. 2014). The accessibility to the ELC system has to be safeguarded by means of working infrastructures and proper connections with the territorial context. To this purpose, the protection of structural aggregates and single structural units is of fundamental importance, since they may interfere with the connection system (Staniscia et al. 2017). In fact, the partial or total collapse of the so-called interfering buildings, as well as strategic ones, may obstruct the necessary evacuation routes and emergency connections after the occurrence of an earthquake.

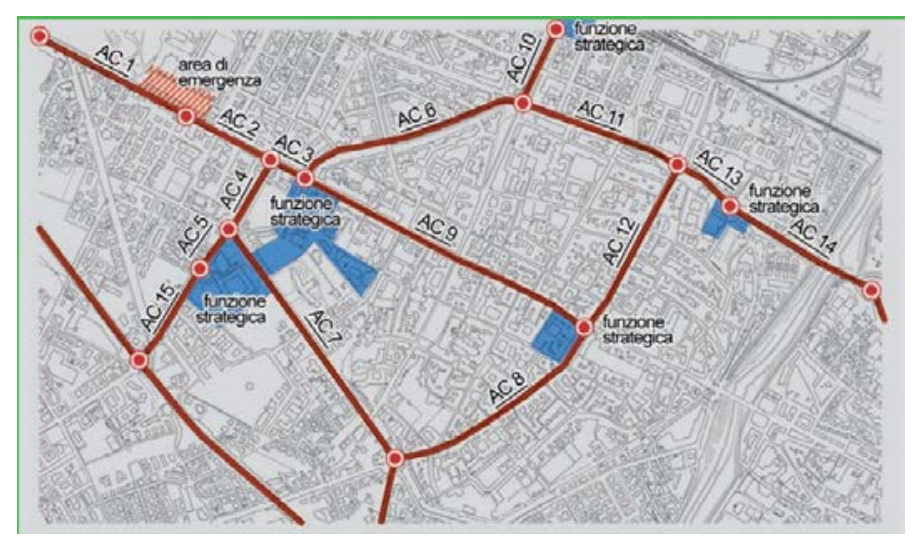

Figure 3. Example of urban Emergency Limit Condition system by Bramerini et al. (2014). 


\subsection{Reliability of the strategic roadway at ELC}

Reliability defines the ability of a system or component to perform its required functions under stated conditions for a specified period of time (Pinto et al. 2004). It can be expressed in general terms as:

$$
R=1-P_{f}
$$

where $P_{f}$ is the failure probability of the system or component.

The built urban environment can be modelled as a mechanical system composed of different elements (buildings, roads, urban infrastructures, etc.) linked one to another in different ways. The failure

probability of the entire complex system has to be computed by combining properly the single elements' failure probabilities. For the specific case of the seismic assessment of strategic urban roadways, the reliability of the ELC system $R_{S}$ expresses the capability of the route to keep its full functionality after the occurrence of an earthquake.

Although there are several methods of combining failure probabilities in complex systems, the easiest approach consists in considering sets of elements arranged in series and/or in parallel. A series system is a configuration in which the entire system collapses if any component of the system fails. In other terms, a series system is as weak as its weakest component. The success of the series system corresponds to the success of each individual component. Given the failure probabilities $P_{f, i}$ of all $i$-th components, if all $n$ components' failure conditions are independent, the reliability of the entire series system at ELC can be expressed as:

$$
R_{S}=\prod_{i=1}^{n}\left(1-P_{f, i}\right)
$$

A parallel system is a configuration in which the entire system works as long as not all the components fail. In other terms, in a parallel configuration the reliability of the total system is higher than the reliability of any single component. The success of the parallel system corresponds to the success of the safest component. Given the failure probabilities $P_{f, i}$ of all $i$-th components, if all $n$ components' failure conditions are independent, the reliability of the entire parallel system at ELC can be expressed asError! Reference source not found.:

$$
R_{S}=1-\prod_{i=1}^{n} P_{f, i}
$$

This paper considers the ELC system for the seismic assessment of strategic urban roadways. A proper approach to evaluate the overall reliability of this type of objects is to consider a series system, i.e. making 
reference to Equation (15). This assumption means that the full functionality of the urban roadways at ELC is strictly related to the safety of the strategic and interfering buildings along them. In fact, the collapse of a single interfering or strategic building, with height equal to the width of the street, may be sufficient to cause the complete obstruction and lack of functioning of the route.

Different values of failure probability $P_{f, i}$ can be accepted for buildings with different Importance Class (IC), as defined in §4.2.5 of Eurocode 8-Part 1 (EN1998-1, 2004). For interfering buildings with IC = I and II, the collapse is not admitted, as well as any other partial failure that may interrupt the serviceability of adjacent connection routes. Their $P_{f, i}$ is evaluated as the probability that the damage grade results higher or equal to $D_{4}$. For buildings with IC = III and IV, or strategic buildings, any activity cannot undergo any interruption, and $P_{f, i}$ is evaluated as the probability that the damage grade results higher or equal to $D_{2}$. The failure probabilities of strategic and interfering buildings are then evaluated in compliance with the DPMs and according to the notation of Equation 13:

$$
\begin{gathered}
\text { interfering building } \rightarrow P_{f, i}=\sum_{k=4}^{5} p_{k} \\
\text { strategic building } \rightarrow P_{f, i}=\sum_{k=2}^{5} p_{k}
\end{gathered}
$$

\subsection{Geographic Information System (GIS) and mitigation of seismic risk}

The final stage of the proposed methodology is based on the use of the GIS, a multi-purpose tool which permits the visual representation of territorial data in large-scale maps (Chang, 2006). The GIS representation can show the results of the seismic risk assessment at urban scale. GIS is a powerful tool to give a global overview of the potential effects of possible seismic events (King, 1995).

The GIS applications aim to highlight urban nodes, routes, buildings and areas that can play a strategic role in case of the occurrence of an earthquake. The GIS tools help to detect critical paths and to facilitate the elaboration of urban risk mitigation plans to safeguard the city's vital lines (Cova, 1999).

The present research includes the processing by means of GIS of the results from seismic vulnerability assessment, in order to identify the most vulnerable elements of the considered ELC system. This operation is necessary to detect clearly the elements whose collapse may obstruct the working of the strategic roadways. GIS is a suitable tool for large-scale planning of further detailed studies, e.g. including detailed inspection and advanced structural analysis, in order to propose ad-hoc interventions to improve the seismic resistance of the most critical interfering and strategic buildings. The GIS-aided 
systems show to be helpful to develop cost- and time-effective policies for large-scale management of seismic retrofitting actions on urban buildings, and thus to mitigate the seismic risk and increase the resilience of the city.

\section{APPLICATION TO THE "ANTIGA ESQUERRA DE L'EIXAMPLE" NEIGHBOURHOOD OF BARCELONA}

Barcelona is the capital of the autonomous community of Catalonia and, after Madrid, is the second largest city in Spain. The focus of the present study is one of the 10 districts of Barcelona called Eixample that covers $7.45 \mathrm{~km}^{2}$ and constitutes a major area of the city centre (Figure 4). The Eixample district includes 8,658 buildings and it is the most populous district of Barcelona and of all Spain in absolute terms (263,558 inhabitants according to the last census of 2015) with a considerable population density (35,300 inhabitants per $\left.\mathrm{km}^{2}\right)$.

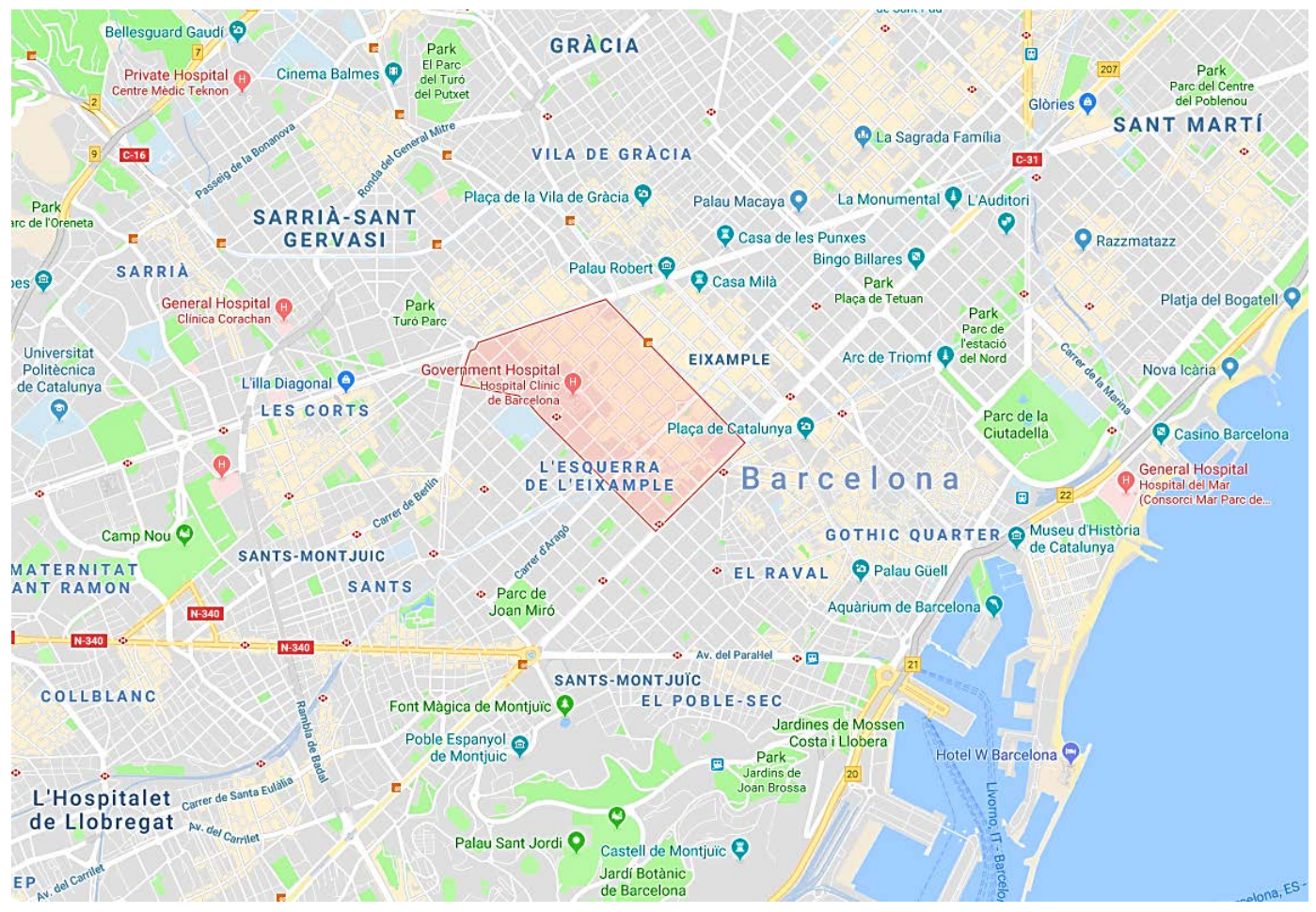

Figure 4. Localization of the "Antiga Esquerra de l'Eixample" neighbourhood of Barcelona (source: Google Maps). 
"Eixample" in Catalan means extension and it was constructed in the late $19^{\text {th }}$ and early $20^{\text {th }}$ centuries as an enlargement of the "Ciutat Vella” (the Old City) to connect it to the nearby villages within the plateau between the sea and the Collserola hills. This major urban expansion project, conceived by Ildefons Cerdà in 1859, was executed after demolishing the medieval walls due to the high population pressure and poor sanitary conditions that were experienced in the Old City. The Eixample district is divided today into six administrative neighbourhoods. The “Antiga Esquerra” (Old Left) was the first part of the Left Eixample to be urbanized.

\subsection{Characteristics of buildings and seismic hazard}

The construction of the Eixample district followed the needs of the increasing population of the city, with buildings considerably growing in height and leading eventually to remarkable population density. The so-called "Illes" (islands), i.e. the typical building blocks, were originally composed of mainly unreinforced masonry structures arranged in large and complex aggregates. The buildings were constructed individually, in an initial stage, and progressively started to share the lateral walls with the neighbour buildings. Each "Illa" has compact shape and is composed of rectangular buildings along the streets and triangular buildings at the chamfered corners (Figure 5). It is worth noticing that the Eixample buildings were designed for gravitational loads only. 

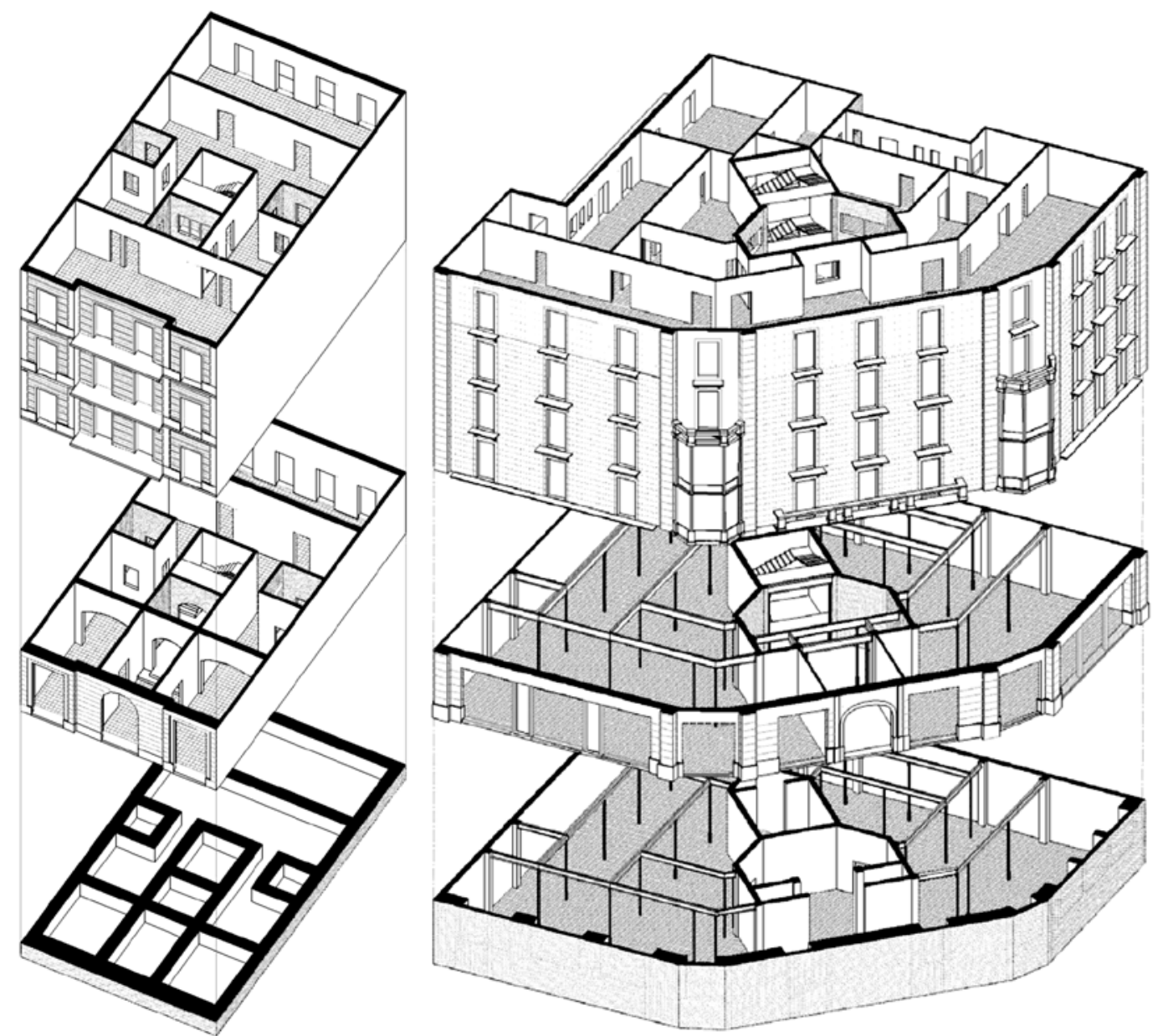

Figure 5. Rectangular buildings and triangular buildings at the chamfered corners of the Eixample's blocks: axonometries by Paricio Casademunt (2001).

Barcelona is located in a low-to-moderate seismic hazard region. The expected seismic intensity in Barcelona is between the grades VI and VII according to the European Macroseismic Scale EMS-98 for a 475 -year return period and (Secanell et al., 2004), i.e. with a 10\% probability of occurrence in 50 years. The corresponding peak ground acceleration is $0.04 \mathrm{~g}$ according to the Spanish seismic code (NCSE-02 2002). The main city soils are classified into four types, see Figure 6. Zone I corresponds to Holocene outcrop with soft soils, near the waterfront and the deltas of the rivers Besós and Llobregat. Zones II and III are intermediate quality soils that correspond to Pleistocene outcrops with different thicknesses of the tertiary substrate. Zone 0 corresponds to Paleozoic and Tertiary rock outcrops (Cid et al. 2001). The equivalent soil types are respectively C, B, B and A as defined by the Eurocode 8 (EN1998-1, 2004; Pujades et al. 2012). The Eixample district is almost entirely located on Zone II and the intensity is VII including the soil effects (Lantada et al. 2009). 


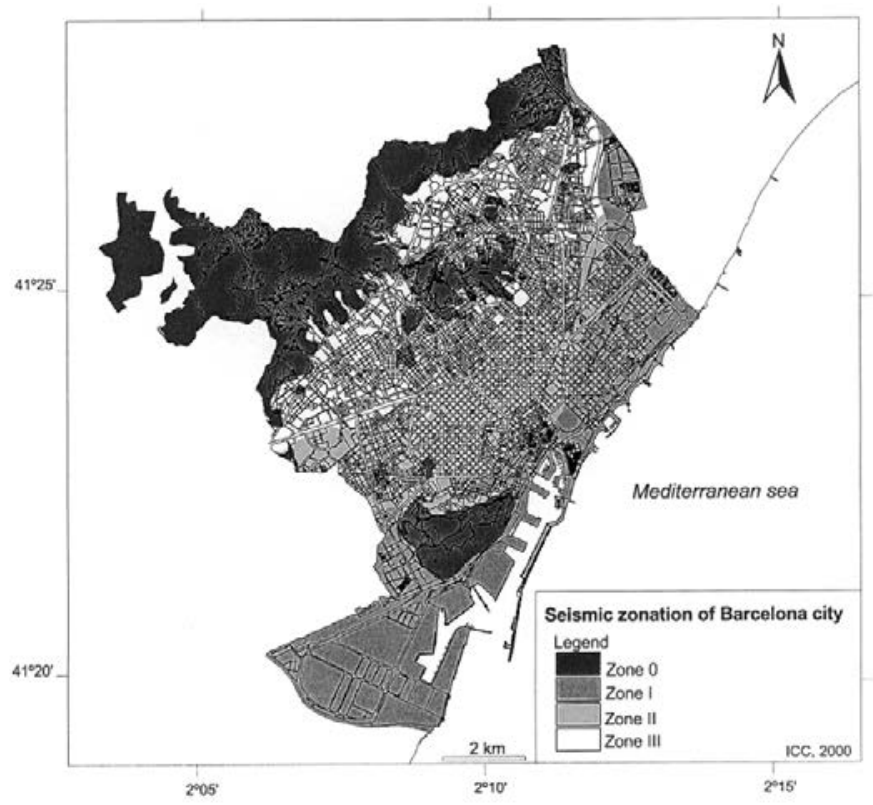

Figure 6. Seismic zoning of the city of Barcelona with identification of four main types of soils (Cid et al. 2001).

The Eixample district is today one of the principal areas of the Barcelona's city centre, where an intense economic activity takes place, population is very dense and several buildings are classified as cultural heritage. More than 70\% of the Eixample’s buildings are still today original unreinforced brick masonry structures. The number of stories is variable. The street and interior façades usually constitute the main bearing walls, together with the interior walls parallel to the façades or the lateral ones between neighbouring buildings. The constructive solution consisting of placing interior metallic pillars and girders in the ground and first floors, in combination with exterior masonry walls, is very common as a way to allow large open spaces for trade and offices, see Figure 5 (Paricio Casademunt 2001). The openings of the façades have considerable size. The openings of the ground level are often non-aligned with those of the upper floors. This peculiar architectural feature causes discontinuities on bearing walls (Figure 7). Load bearing walls are very slender and often lack orthogonal restraining walls. Moreover, neighbouring floors often present very different spans, inducing important flexure actions to the load bearing walls. All these constructive characteristics increase the overall vulnerability of the Eixample’s buildings, as also highlighted in previous works (Barbat et al. 2006, Gonzalez-Drigo et al. 2015).

The floors of unreinforced masonry buildings are typically made of timber or steel beams connected by small barrel vaults built with ceramic tiles (Figure 8). These types of floors have a reduced in-plane and out-of-plane stiffness, as well as limited strength to axial forces and bending moments. 

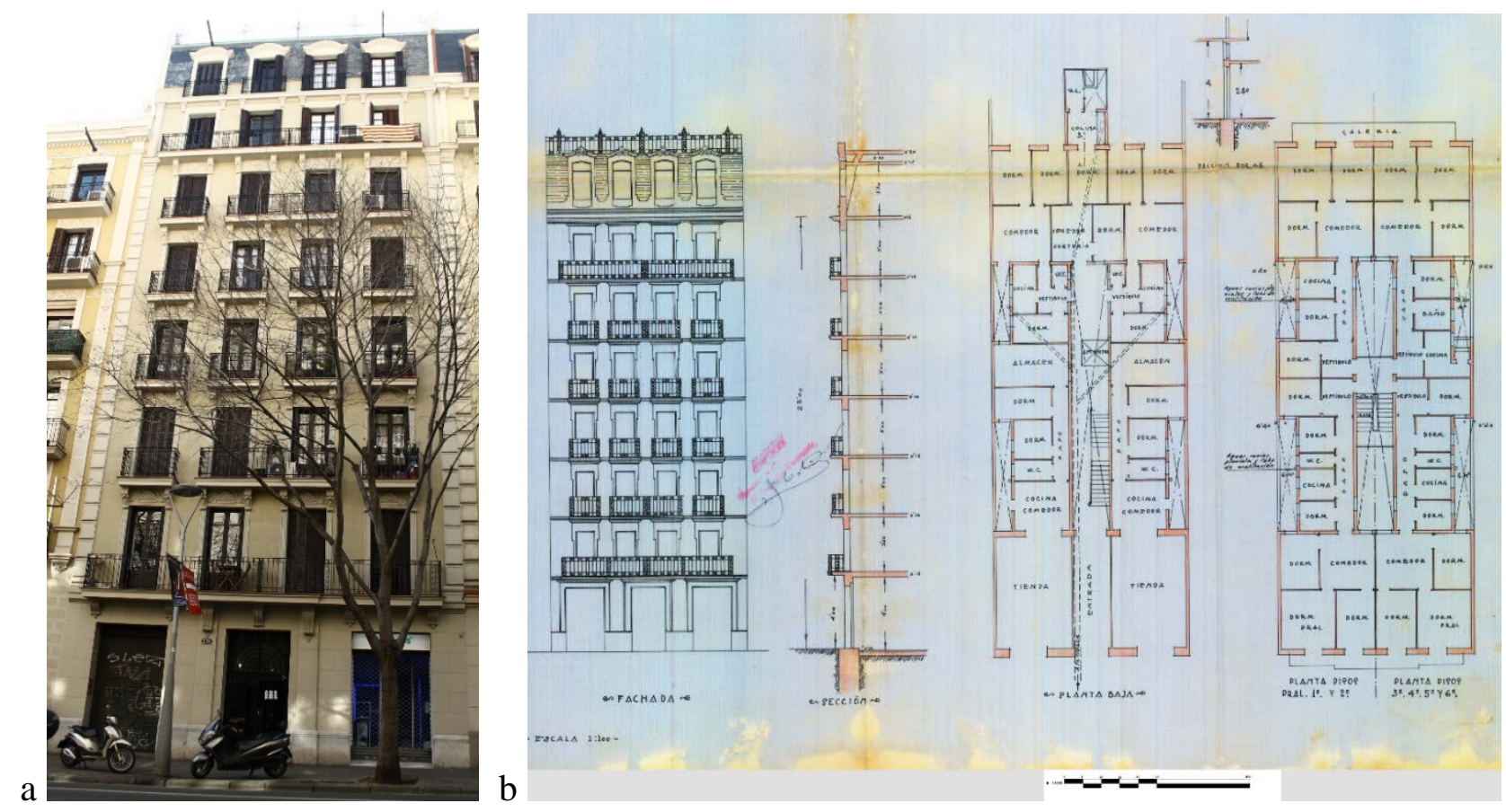

Figure 7. Typical masonry building of the Eixample district, located in Villarroel Street 231 (source: public archives of Barcelona City municipality): view of the street façade (a) and original drawings of street façade, vertical section and plans (b).
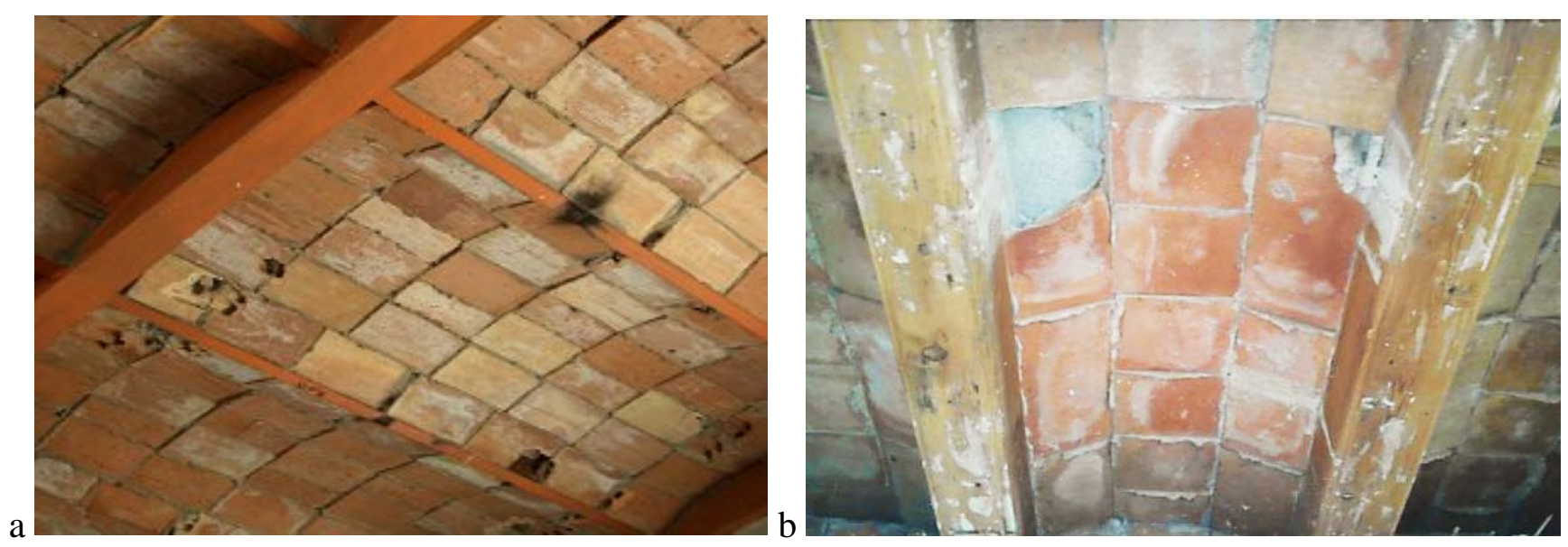

Figure 8. Examples of typical vaulted floor systems of unreinforced masonry buildings of the Eixample district with a) steel beams and b) timber beams.

Less than 30\% of existing buildings in the Eixample district consist of RC structure (Figure 9) built mainly after the sixties. The structural system consists mostly of RC columns and ribbed or waffle slab floors. This structural solution is not adequate from the point of view of the seismic behaviour since it is characterized by low structural ductility (Barbat et al. 2006, 2008). Some of the buildings present RC frames extending from foundation level to the first floor, i.e. in levels hosting trade activities in open 
spaces. Upper floors have normally residential function and the vertical load bearing systems are unreinforced masonry walls from the first floor up to the roof. Due to this particular layout, these buildings may be considered more properly as RC-masonry mixed structures, instead of pure RC structures. This peculiar building typology exhibits strong irregularity in elevation due to the sudden change of the structural system at the first floor level.

Another source of seismic vulnerability is the later addition in the late $20^{\text {th }}$ century of the so-called “remontes” (elevations), both in RC and unreinforced concrete buildings, with the consequent addition of mass on top and height irregularities.

Based on the aforementioned considerations, it is evident that a low-to-moderate earthquake may reveal to be extremely dangerous for the Eixample district. Even though the hazard is limited, the vulnerability and exposure are considerably high due to the peculiar structural systems and very dense population.
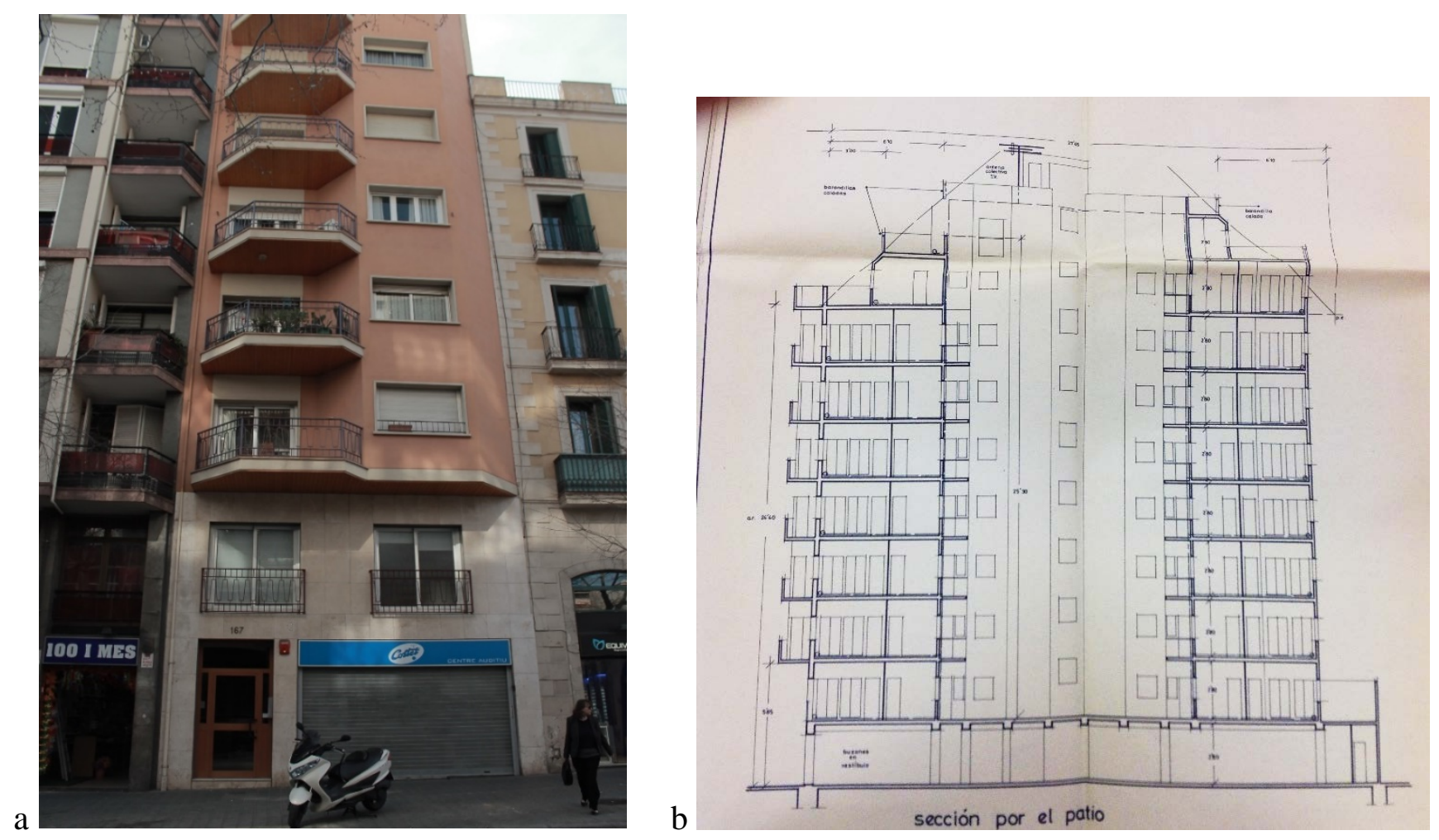

Figure 9. Typical reinforced concrete building of the Eixample district, located in Villarroel Street 167: façade (a) and original drawings of vertical section (b).

\subsection{Description of the study area}

The “Antiga Esquerra de l'Eixample” is a $1.23 \mathrm{~km}^{2}$ urban neighbourhood with a population of 41,664 inhabitants and a density of 33,800 inhabitants per $\mathrm{km}^{2}$ at the last census of 2015. This study focuses on 
the seismic risk assessment at the ELC of the area surrounding one of the most important communication axis of Barcelona. The considered study area of $27.700 \mathrm{~m}^{2}$ is located around the Hospital Clinic of Barcelona (Figure 10), the main public healthcare provider in this zone of influence that serves a population of 540,000 inhabitants. The Emergency Department is located in the main 7-floor building, overlooking Villaroel Street.

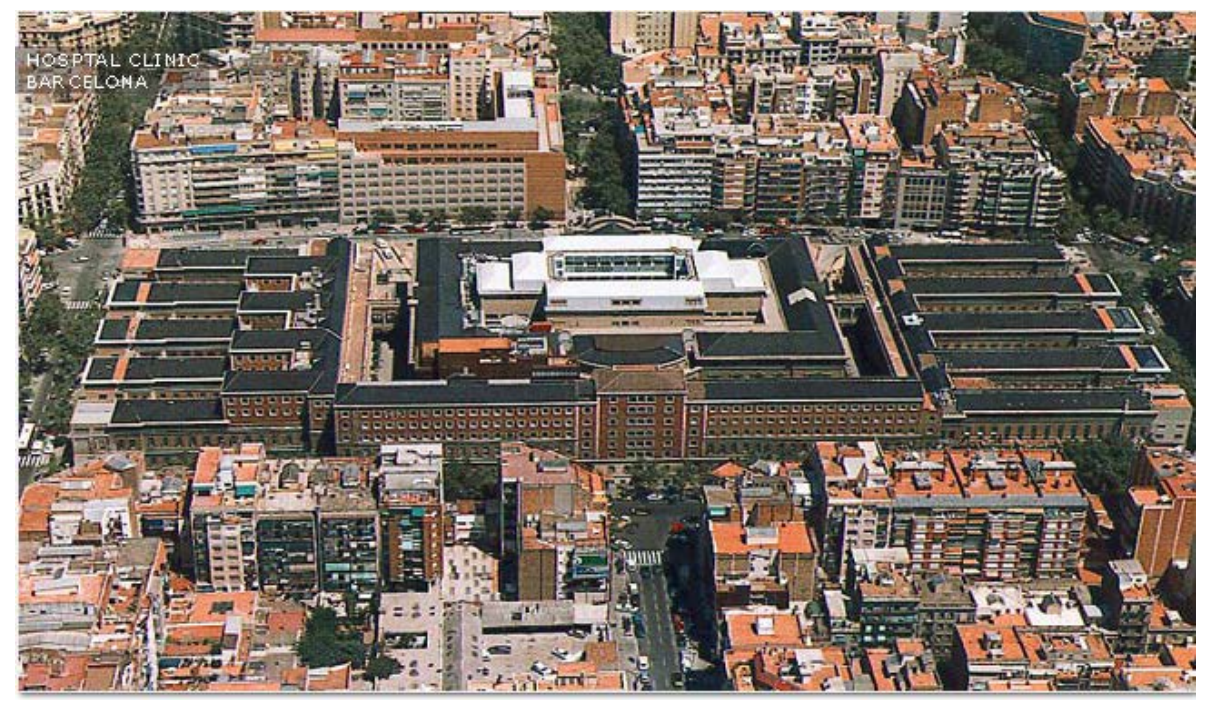

Figure 10. Aerial view of the Hospital Clinic, Antiga Esquerra de l'Eixample, Barcelona.

The urban texture of the Eixample district was studied in order to detect the elements constituting the ELC system, which are all reported in Figure 11. The local Civil Protection Department classified Villarroel and Aragon Streets as emergency connection roads (numbers 1 and 2 in Figure 11). These roads have widths of $20 \mathrm{~m}$ and $30 \mathrm{~m}$, respectively. Both the main building of the hospital and the Primary Healthcare one, located between Villaroel and Casanova streets, were considered as strategic buildings. The squares Letamendi, Gall, Redondo, as well as the parks Jardins de Marcos and of the University of Barcelona, were defined as emergency areas. A total of 44 buildings were selected and analysed as interfering buildings, according to the ELC guidelines by Bramerini et al. (2014), since their collapses may jeopardize the functionality of the ELC system by obstructing the access to the Hospital Clinic of Barcelona through the two main emergency roadways, i.e. the aforementioned Villarroel and Aragon Streets. It must be noticed that all the interfering buildings of the ELC system were identified along Villarroel street, since the buildings along Aragon Street have total height lower than the width of the street and thus their collapse would not obstruct the whole width of the roadway. The Hospital Clinic 
was not considered either as an interfering building, since it has been recently subjected to structural interventions.

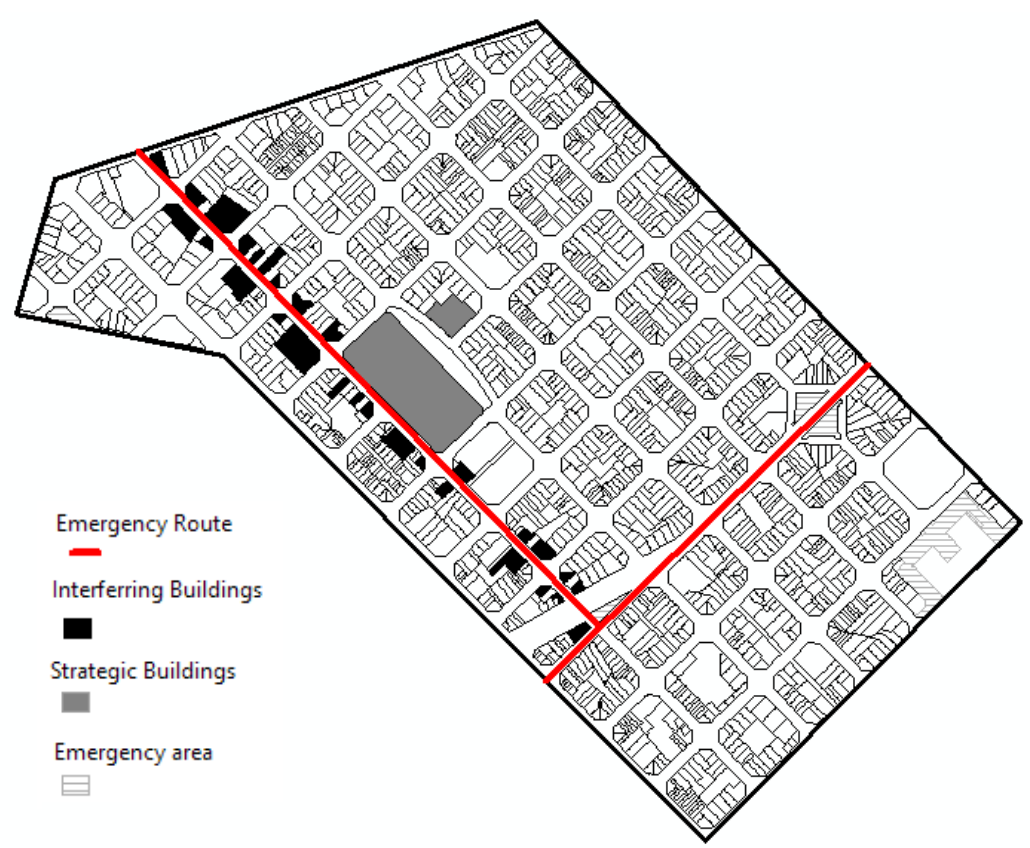

Figure 11. ELC system of the Antiga Esquerra de l’Eixample neighborhood (GIS map).

\subsection{Seismic vulnerability of interfering buildings}

An important and time-consuming phase of the research was the creation of the database, reporting all the data necessary for the evaluation of the seismic vulnerability of the 43 interfering buildings according to the vulnerability index methodology proposed by GNDT (GNDT 1986, 1993, 1999). This information was extracted by crossing the information from the land registry plots, the historical documents available in public archives of Barcelona City municipality (Arxiu Municipal Contemporani, Arxiu Municipal del Districte de l'Eixample, Departament d'Informació i Documentació - Oficina d'Informació Urbanística), the Territorial Information System (Departament d'Estadística de l’Ajuntament de Barcelona), the archives of professional societies (Arxiu Históric del Col·legi d'Arquitectes de Catalunya) and previous studies (Paricio Casademunt 2001).

Even though the amount of the available information was sometimes variable, it was possible to extract detailed data, from the original historical building site documents and technical drawings, about the age of the buildings, the structural typology, the number of floors, the construction materials, the design loads 
and the morphology of structural members (walls, floors, foundations), among other aspects. The level of detail of the sought information revealed to be appropriate to inform the second level forms proposed by the GNDT. Figure 12 shows the GIS maps plotting the construction year and the structural typology of the considered interfering buildings.
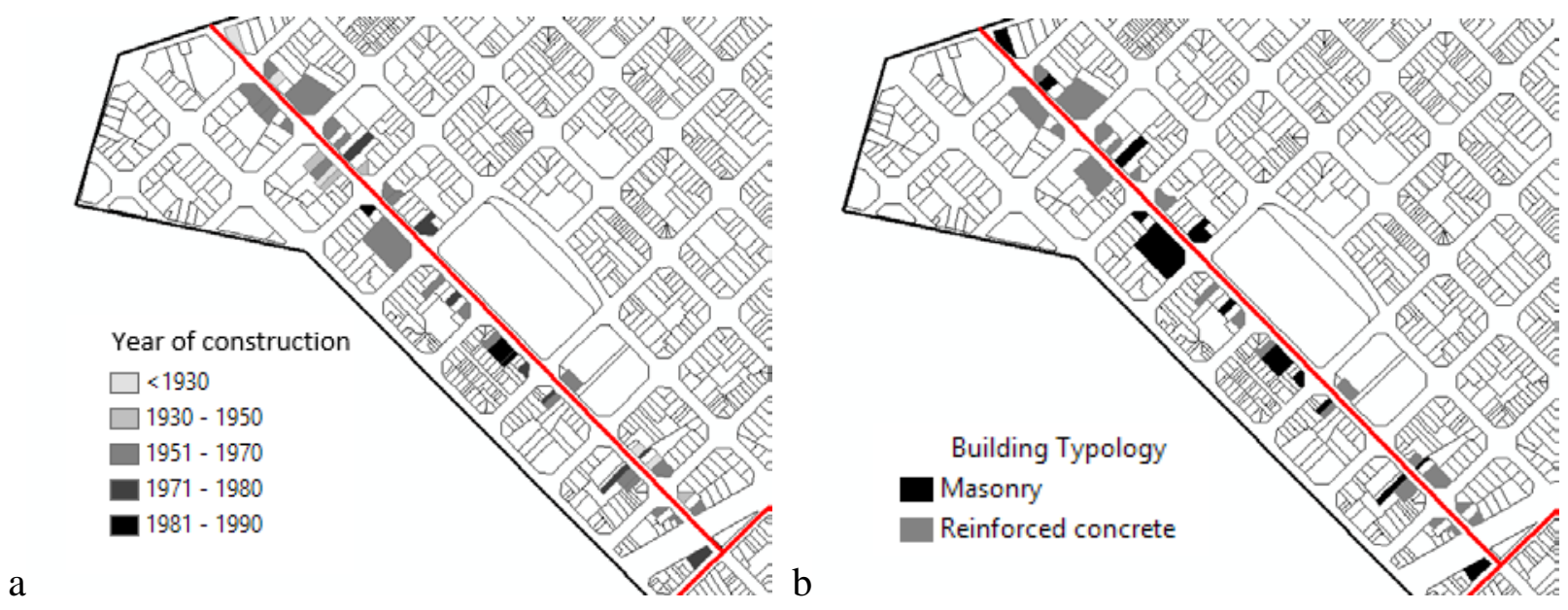

Figure 12. Year of construction (a) and Construction Typology (b) of the interfering buildings under investigation of the Antiga Esquerra de l'Eixample neighborhood (GIS map).

Once having computed the vulnerability indexes in the principal directions $I_{V x}, I_{V y}$ of each interfering building by using Equation (1), the directional variability of the vulnerability index $I_{V \alpha}$ (Equation 3) was calculated for an earthquake incidence direction $\alpha$ from $0^{\circ}$ to $360^{\circ}$. The direction $\alpha=\theta$ showed to be that of maximum overall vulnerability of the investigated urban system.

GIS software was used to provide visual maps of the "Antigua Esquerra de l'Eixample” ELC system, reporting a quick overview of the vulnerability indexes of its buildings, see Figure 13a. Figure 13b shows the percentage of buildings with a given vulnerability index. As it can be noticed, the $82 \%$ of buildings presents a vulnerability index within the range from 41 to 60 according to the GNDT forms. The GIS map clearly highlight the potential vulnerability of the interfering buildings and thus on the strategic urban roadway serving the Hospital Clinic of Barcelona.

The collapse probability of each interfering building was calculated eventually by considering Equation (17a). The reliability of the entire ELC system was evaluated according to the series model of Equation (15). Figure 14 presents the trend of the variation of the reliability for different values of macro-seismic intensities $I_{E M S-98}$. It is possible to notice that the adopted series model of the ELC system yields a 16\% reliability for the expected seismic intensity in the Eixample district for a 475 year return period, i.e. 
$I_{E M S-98}=$ VII. This result suggests that the route to the Hospital Clinic might be interrupted at the ELC, at least according to the simplified approach envisaged by the present work.

For this reason, the next section presents a tentative proposal as a first quick assessment to plan further actions and large-scale strengthening interventions, in order to improve the response of the ELC system by mitigating its seismic vulnerability.

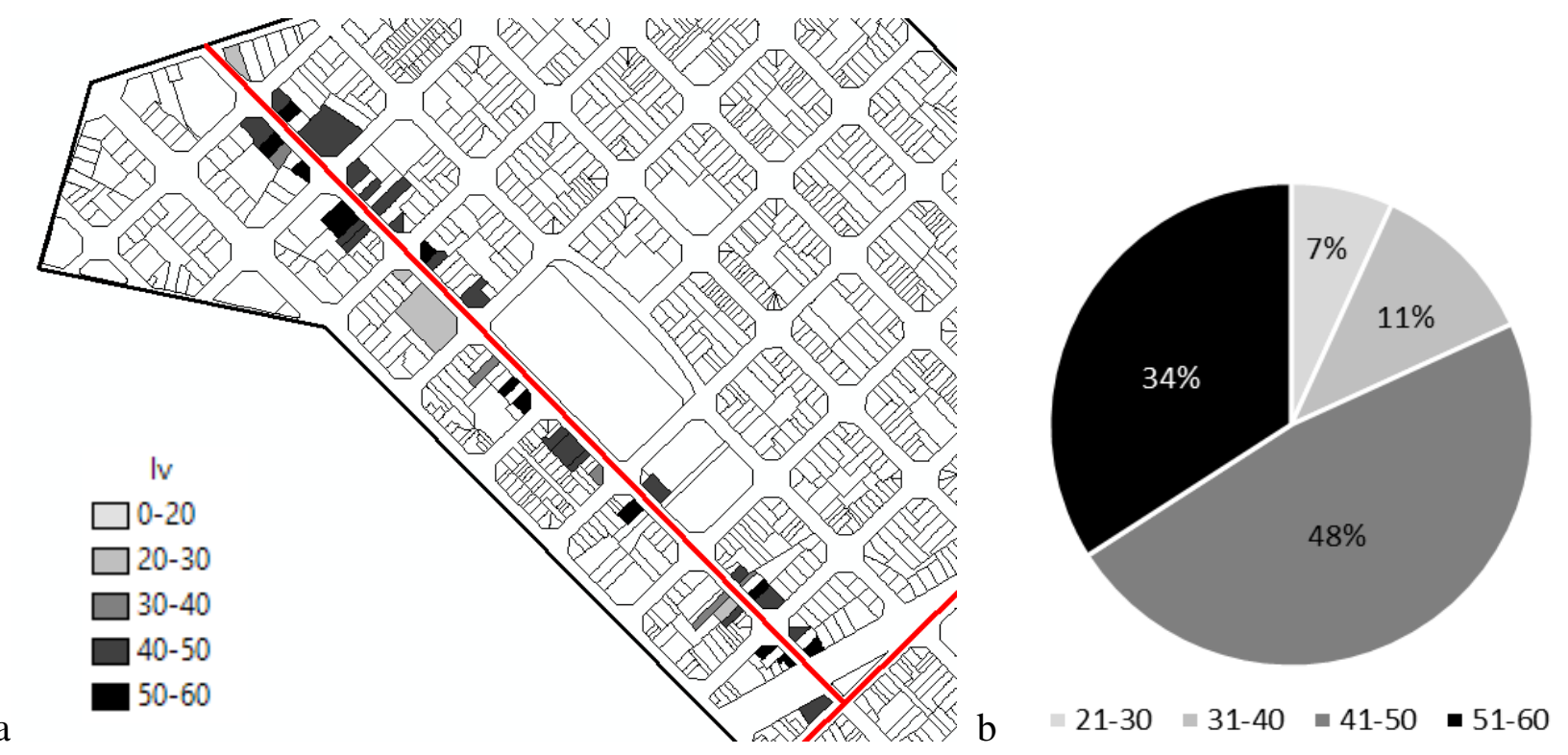

Figure 13. Vulnerability index map of the ELC system (a) and percentage of buildings with a given vulnerability index (b).

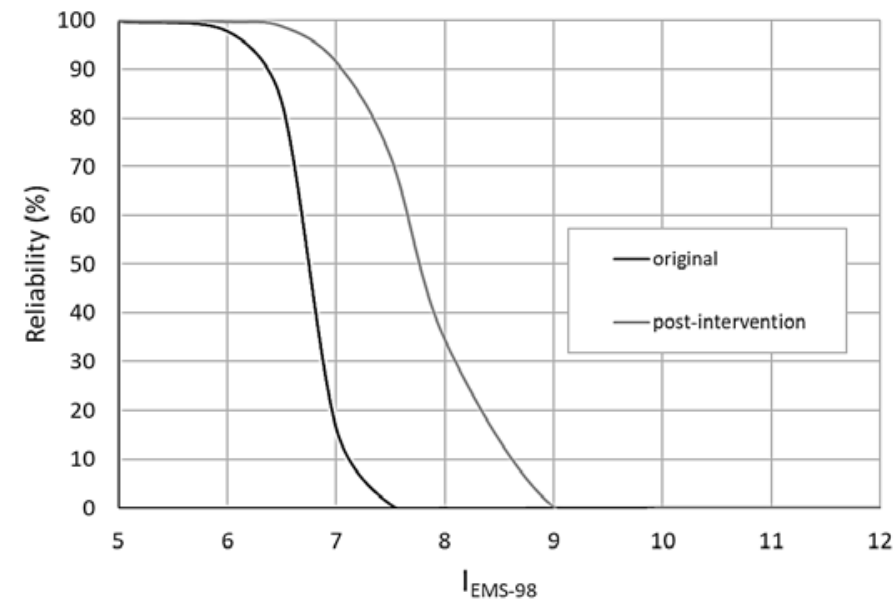

Figure 14. Reliability of the ELC system for variable macro-seismic intensity $I_{E M S-98}$ before and after the seismic risk mitigation interventions. 


\subsection{Mitigating the seismic risk at the ELC}

The definition of the necessary interventions to reduce the seismic vulnerability of single buildings usually require detailed inspection of their structural members and experiments on existing materials, as well as sophisticated structural analysis. It is evident that developing the same activities in all the structures of an entire urban system would not be affordable in terms of time and costs. For this reason, the large-scale policies for urban seismic risk mitigation should be carefully planned in order to assess the feasibility of the intended actions, compare different alternatives, and optimize resources and time. This section provides a simple tool to orient the development of seismic mitigation strategies, in order to assess the overall impact of possible interventions at the urban scale. Following the methodology proposed in the previous sections to identify the most vulnerable structures of the built heritage, the further step is the simulation of realistic seismic retrofit actions to assess their possible ameliorative effect on the seismic risk reduction of the urban system.

Standard strengthening interventions were tentatively proposed for both masonry and RC interfering buildings to mitigate the seismic vulnerability of the ELC system of the "Antiga Esquerra de l'Eixample" neighbourhood. Seismic retrofitting strategies, when applied to existing buildings at a large scale, can produce a remarkable impact on the urban seismic risk mitigation (Ferreira, Maio and Vicente, 2017). The criteria for the choice of the interventions depend on the detected structural deficiencies and the typology of the considered buildings.

A large-scale analysis of the most frequent structural vulnerabilities of the investigated buildings allows the definition of necessary criteria for the seismic retrofit interventions. As for the masonry structures of the Antiga Esquerra de l'Eixample, the recurrent reduced thickness of main and secondary walls causes considerable slenderness to the load-bearing vertical members. The application of Textile Reinforced Mortar (TRM) is proposed at both sides of the walls to increase their thickness, together with their inplane and out-of-plane strengths. TRM constitutes a time and cost efficient strengthening technique (Triantafillou 2016, Ismail and Ingham 2016, Lignola et al. 2017) that could be easily implemented on numerous urban buildings, also providing possible energy saving benefits (Triantafillou et al., 2017). TRM parallel layers could be built at both sides of the walls and then connected together by means of transversal connectors. Strengthened walls may require also strengthening works to the foundations systems. TRM retrofit can provide better seismic performance and reduce the vulnerability of the upgraded masonry buildings. The ameliorative effects can be taken into account by the vulnerability index method (GNDT 1993), since the deployment of TRM retrofit can imply important reductions of the class scores related to the “conventional strength” parameter (P3), and the "quality of the resisting 
system" parameter (P2), due to relevant class enhancement within each parameter. The "conventional strength" is a structural parameter with major impact on the overall evaluation of the vulnerability index, having a weight $w_{3}=1.5$, see Table 1 . The parameter P3 evaluates approximately the seismic safety level of the building compared to the reference seismic forces. A consequence of the implementation of TRM to the Eixample's buildings is the improvement of the P3 class due to the increase of the shear strength in the retrofitted material, as well as of the thickness of the walls. The GNDT (1993) suggests reference values of shear strength for several typologies of both unreinforced and retrofitted masonry. In addition, all retrofitted masonry buildings can improve to the " $\mathrm{A}$ ” class within parameter P2 since TRM provides further homogeneity and regularity to the resisting material.

In the case of RC-masonry mixed structures, i.e. buildings with RC frames at lower levels and masonry load bearing walls at upper levels, the proposed interventions focus on stiffening and strengthening the $\mathrm{RC}$ columns of the ground floor, as well as connecting them to the upper masonry structure. In particular, concrete jacketing of RC columns are proposed in order to increase the resistant area of the ground floor. Concrete jacketing is a recurrent technique for seismic retrofit of RC columns that has been extensively documented in the literature (FEMA 547-2006, Campione et al. 2014, Minafò 2015, Triantafillou 2016). Concrete jacketing confines the existing RC columns with an additional concrete layer and additional external steel stirrups and longitudinal bars. The original column and the external jacketing are connected by means of transversal steel connectors. Jacketed RC columns may require strengthening works to foundations systems. This intervention can provide better seismic performance to the RC-masonry mixed buildings and this can be reflected in higher class scores related to the "conventional strength" (P3), the “quality of the resisting system” (P2), and the “configuration in elevation” (P7) (GNDT 1986). The required thickness of the concrete jacketing was calculated in each Eixample's building in order to achieve the desired regularity in elevation, with homogeneous structural stiffness from ground to upper levels. The increase of the cross section of the RC columns produces a reduction of the class score $C_{v 3}$ (see Table 3) in the retrofitted RC buildings, since parameter P3 is directly related to the total shear resistance of the structure. In addition, all retrofitted RC buildings can improve to the "A" class within parameter P2 since concrete jacketing can ensure the improvement of the quality of the resisting system, and also within parameter P7 since the retrofitted structure becomes regular in elevation.

Ten masonry buildings and nine RC buildings were selected to be strengthened among the most vulnerable interfering buildings. The reliability of the post-intervention ELC system was evaluated in order to assess the overall mitigation effects. Figure 14 shows a reliability of $92 \%$ for $I_{E M S-98}=$ VII, 
compared to the $16 \%$ of the original ELC system. This means that strengthening 19 out of 44 interfering buildings may produce a meaningful improvement of the entire ELC system reliability.

Figure 15a shows the vulnerability indexes map for interfering buildings of the post-intervention ELC system. The mitigation effects due to the seismic strengthening interventions are remarkable. Figure 15b shows the percentage of interfering buildings of the post-intervention ELC system with a given vulnerability index. As it can be noticed, the percentage of buildings with vulnerability index in the range from 41 to 60 is 9\%, a much lower percentage than in the original ELC system. It is evident as the seismic retrofit interventions can provide remarkable benefits, compared to the original ELC system, see Figure 13.

The outcomes of the study reveal that the proposed approach can constitute a quick useful tool to evaluate the feasibility of sustainable mitigation plans for seismic risk mitigation of urban areas. However, it is worth mentioning that this preliminary approach should be naturally followed by more detailed studies to improve the knowledge about the buildings to be retrofitted, until leading to the optimum choice of the seismic retrofit interventions.

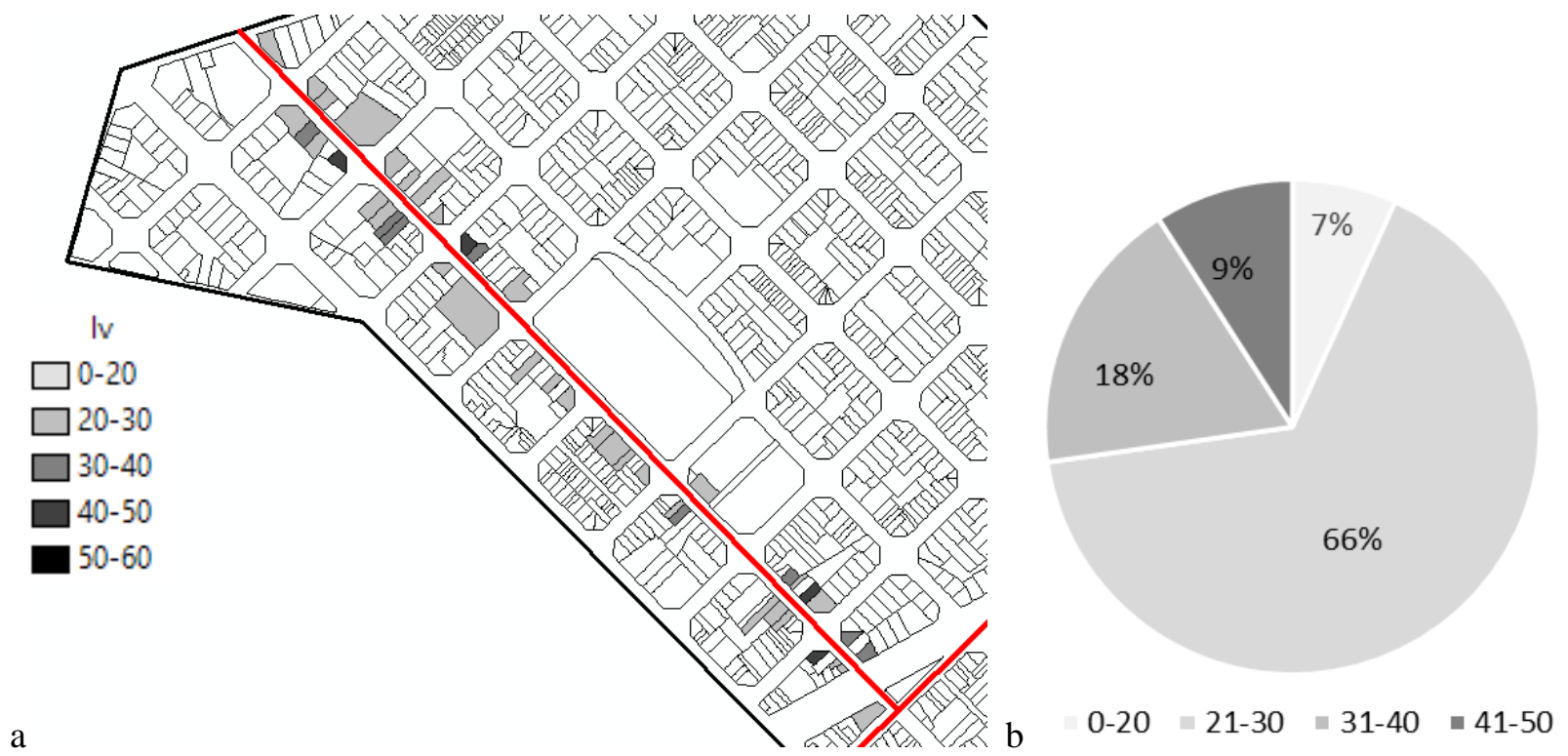

Figure 15. Vulnerability index map of the post-intervention ELC system (a) and percentage of buildings with a given vulnerability index (b). 


\section{CONCLUSIONS}

The development of seismic risk evaluation and mitigation strategies is being regarded at present as a task of utmost importance in order to ascertain a satisfactory response of urban systems against earthquakes. In addition to promote earthquake resistant new construction, modern policies are also prioritizing the rehabilitation of urban centres as a way to ensure satisfactory seismic performance to existing buildings and urban facilities.

The focus of this work has been the proposal of a novel quick approach to assess the influence of the possible collapse of strategic/interfering buildings on the serviceability of strategic urban roadways after an earthquake. The combined use of the vulnerability index method and macro-seismic earthquake intensity has provided a suitable expeditious procedure to afford a large-scale evaluation of the seismic risk of buildings along strategic routes. A straightforward mechanical model has been used to correlate in a simple manner the failure probability of the buildings with the reliability of the strategic roadway. The presented tool may support decision-makers to assess the feasibility of large-scale seismic risk mitigation policies by optimizing time and resources. The proposed model can constitute a first step towards the identification of the most vulnerable buildings deserving further analyses, prior to the planning of proper seismic retrofit interventions at the urban level.

The feasibility of the approach proposed for seismic risk evaluation and mitigation has been verified through its application to a real urban neighbourhood. The Antiga Esquerra de l'Eixample neighborhood has been chosen as representative case study due to the presence of the roadway to the hospital, in addition to its strategic and cultural value for the city of Barcelona. After the definition of the Emergency Limit Condition (ELC) system, based on the identification of the Minimum Urban Structure (MUS), the proposed methodology for seismic risk assessment has proved to be simple and effective.

The application of the proposed methodology to the Antiga Esquerra de l'Eixample neighborhood has revealed a not satisfactory reliability for the expected earthquake intensity $I_{E M S-98}=$ VII with 475-year return period in Barcelona. The proposal of proper seismic strengthening interventions, for 19 selected interfering buildings out of 44 , has shown the possible increase of the reliability of the post-intervention ELC from $16 \%$ to $92 \%$. The percentage of buildings with vulnerability index in the range from 41 to 60 has decreased from $82 \%$ to $9 \%$ in the post-intervention ELC system. These results will be updated and improved in the future with additional knowledge on the buildings and more sophisticated mechanical models to evaluate more precisely their mutual interaction and interdependence. 
A critical stage of the research has been the data survey on buildings, which always constitutes a rather time-demanding process for complex urban systems. The historical archives of the city have provided valuable information about buildings' constructive typologies. Even though the obtained information has revealed to be appropriate for the second level forms proposed by the GNDT, the collection of historical documents in paper format has constituted a very time-consuming activity. This stage might result even more time demanding in cities with limited access archives. For this reason, local administrations and public authorities could promote local initiatives to gather and organize the large amount of data needed for studies on the seismic safety of the built urban environment. An interesting possibility may be offered by the involvement of citizens or voluntaries whose cooperation could help to extend the study from the neighborhood level to the district one, and then to the whole city. Similar initiatives may contribute to make local communities aware of their central role for the establishment of the public well-being and safety.

Besides the improvement of the survey strategies of the existing building stock, future work is required to extend the vulnerability index evaluation forms to different construction typologies, as well as to include additional criteria allowing a more explicit assessment of the benefits of ameliorative interventions. Another interesting possibility is the application of the methodology to other urban limit conditions, in addition to the ELC, and to other urban facilities and infrastructures, such as water supply systems, pipelines, communication networks, etc.

The use of GIS system to gather all the information and simulations of possible risk scenarios is considered an essential part of the proposed methodology. The database and georeferenced maps obtained for the Antiga Esquerra de l'Eixample will be improved in the future by the addition of updated information regarding both the unassessed buildings and already assessed ones, leading eventually to optimized risk mitigation measures and civil protection planning.

\section{ACKNOWLEDGEMENTS}

The authors gratefully acknowledge the financial support from the MINECO (Ministerio de Economia y Competitividad of the Spanish Government) and the ERDF (European Regional Development Fund) through the MULTIMAS project (Multiscale techniques for the experimental and numerical analysis of

the reliability of masonry structures, ref. num. BIA2015-63882-P), as well as the FAR fundings (Fondo di Ateneo per la Ricerca) of the University of Ferrara through the project HC-LIVE (Historical Centers 
Livable and Sustainable, 2015). The authors wish to acknowledge also the Erasmus+ programs allowing the bilateral agreement between the University of Ferrara and the Technical University of Catalonia.

\section{REFERENCES}

1) Armaş, I. 2012. Multi-criteria vulnerability analysis to earthquake hazard of Bucharest, Romania. Natural Hazards, 63(2):1129-1156.

2) Athmani, A.E., Gouasmia, A., Ferreira, T.M., Vicente, R., and Khemis, A. 2015. Seismic vulnerability assessment of historical masonry buildings located in Annaba city (Algeria) using non ad-hoc data survey. Bulletin of Earthquake Engineering, 13(8):2283-2307.

3) Badawy, A., Korrat, I., El-Hadidy, M., and Gaber, H. 2017. Update earthquake risk assessment in Cairo, Egypt. Journal of Seismology, 21(4):571-589.

4) Barbat, A., Pujades, L.G., and Lantada, N. 2006. Performance of buildings under earthquake in Barcelona, Spain. Comput Aided Civil and Infrastructure Engineering, 21:573-593.

5) Barbat, A., Pujades, L.G., and Lantada, N. 2008. Seismic damage evaluation in urban areas using the capacity spectrum method: Application to Barcelona. Soil Dynamics and Earthquake Engineering, 28:851-865.

6) Basaglia, A., Aprile, A., Pilla, F., and Spacone, E. 2016. Computer-aided risk assessment at urban scale. Model definition and validation on a case study. In Proceedings of ECCOMAS Congress 2016, 5977-5986. Hersonissos, Crete Island.

7) Basaglia, A., Aprile, A., Spacone, E., and Pilla, F. 2018. Performance-based seismic risk assessment of urban systems. International Journal of Architectural Heritage, present volume.

8) Benedetti, D., and Petrini, V. 1984. Sulla vulnerabilità sismica di edifici in muratura: Un metodo di valutazione (in Italian). L'Industria delle Costruzioni, 149(18):66-78.

9) Bernardini, A., Giovinazzi, S., Lagomarsino, S., and Parodi, S. 2007. The vulnerability assessment of current buildings by a macroseismic approach derived from the EMS-98 scale. In Proceedings of Third National Congress of Earthquake Engineering, Girona, Asociación Española de Ingeniería Sísmica. 
10) Bramerini, F., and Castenetto, S. 2014. Manuale per l'analisi della Condizione Limite per l'Emergenza (CLE) dell'insediamento urbano (in Italian). Roma: BetMultimedia.

11) Burton, H.V., Deierlein, G., Lallemant, D., and Lin, T. 2016. Framework for Incorporating Probabilistic Building Performance in the Assessment of Community Seismic Resilience. Journal of Structural Engineering ASCE, 142(8):C4015007.

12) Calvi, G.M., Pinho, R., Magenes, G., Bommer, J.J., Restrepo-Vélez, L.F., and Crowley, H. 2006. Development of seismic vulnerability assessment methodologies over the past 30 years. ISET Journal of Earthquake Technology, 43(3):75-104.

13) Campione, G., Fossetti, M., Giacchino, C., and Minafò, G. 2014. RC columns externally strengthened with RC jackets. Materials and Structures/Materiaux et Constructions, 47(10):17151728.

14) Cardona, O.D., Van Aalst M.K, Birkmann, J., Fordham, M., McGregor, G., Perez , R., Pulwarty, R.S. Schipper, E.L.F., and B.T. Sinh (2012). “Determinants of risk: exposure and vulnerability”. In: Managing the Risks of Extreme Events and Disasters to Advance Climate Change Adaptation. A Special Report of Working Groups I and II of the Intergovernmental Panel on Climate Change (IPCC). Cambridge University Press, Cambridge, UK, and New York, NY, USA, pp. 65-108.

15) Castilla Marne J. 2010. Catalogación y levantamiento gráfico de fachadas de las manzanas del Eixample (in Spanish). Proyecto Final de Carrera. Universitat Politècnica de Catalunya, Barcelona, Spain.

16) CETE Méditerranée DREC/SVGC-SIG 2008. Comparaison de méthodes qualitatives d'évaluation de la vulnérabilité des constructions aux séismes. Plan séisme - action 2.4.7. Guide des méthodes de diagnostics de la résistance des bâtiments aux séismes. Convention MEDD/CETE $n^{\circ} \mathrm{CV} 05000107$ (in French). Available file://C:/Users/luca.pela/Desktop/comparaison_methodes_vulnerabilite_sommaire.pdf

17) Chang, K.T. 2006. Introduction to Geographic Information System. New York: McGraw-Hill.

18) Crichton, D. 1999. The Risk Triangle. In Natural Disaster Management. Edited by Ingleton J., 102103. London: Tudor Rose.

19) Cid, J., Susagna, T., Goula, X., Chavarria, L., Figueras, S., Fleta, J., Casas, A., and Roca, A. 2001. Seismic Zonation of Barcelona Based on Numerical Simulation of Site Effects. Pure Applied 
Geophysics, 158:2559-2577.

20) Coburn, A.W., and Spence R. 2002. Earthquake protection. Chichester: Wiley.

21) Cova, T.J. 1999. GIS in emergency management. Geographical information systems, 2:845-858.

22) D'Ayala, D.F., and Paganoni, S. 2011. Assessment and analysis of damage in L'Aquila historic city centre after 6th April 2009. Bulletin of Earthquake Engineering, 9(1):81-104.

23) EN1998-1 2004. Design of structures for earthquake resistance. Part 1: General rules, seismic actions and rules for buildings. Brussels: CEN.

24) FEMA547 2006. Techniques for the Seismic Rehabilitation of Existing Buildings. Washington, D.C: Federal Emergency Management Agency.

25) Ferreira T.M., Vicente R., Mendes Silva J.A.R., Varum H., and Costa, A. 2013. Seismic vulnerability assessment of historical urban centres: case study of the old city centre in Seixal, Portugal. Bulletin of Earthquake Engineering, 11:1753-1773.

26) Ferreira, T.M., Maio, R., and Vicente, R. 2017. Analysis of the impact of large scale seismic retrofitting strategies through the application of a vulnerability-based approach on traditional masonry buildings. Earthquake Engineering and Engineering Vibration, 16(2):329-348.

27) Ferreira, T.M., Maio, R., and Vicente, R. 2017. Seismic vulnerability assessment of the old city centre of Horta, Azores: calibration and application of a seismic vulnerability index method. Bulletin of Earthquake Engineering 15(7):2879-2899.

28) Formisano, A., Florio, G., Landolfo, R. and Mazzolani, F.M. 2011. Numerical calibration of a simplified procedure for the seismic behaviour assessment of masonry building aggregates. In Proceedings of the $13^{\text {th }}$ International Conference on Civil, Structural and Environmental Engineering Computing. Chania, Crete.

29) Formisano, A., Florio, G., Landolfo, R. and Mazzolani, F.M. 2015. Numerical calibration of an easy method for seismic behaviour assessment on large scale of masonry building aggregates. Advances in Engineering Software, 80:116-138

30) Giovinazzi, S., and Lagomarsino, S. 2004. A macro-seismic model for the vulnerability assessment of buildings. In Proceedings of 13th WCEE. Vancouver, Canada. 
31) Giovinazzi, S. 2005. The vulnerability assessment and the damage scenario in seismic risk analysis. PhD Thesis, University of Florence and Technical Unviersity of Braunschweig.

32) GNDT 1986. Scheda di vulnerabilità di $2^{\circ}$ livello (cemento armato), in Italian. Available at: https://emidius.mi.ingv.it/GNDT2/Strumenti/Schede/Schede_vulnerabilita/scheda_secondo_livell o_ca_86.pdf

33) GNDT 1993. Rischio sismico di edifici pubblici. Parte Ia Aspetti metodologici. Appendice n.1 Manuale per il rilevamento della vulnerabilità sismica degli edifici. Istruzione per la compilazione della scheda di $2^{\circ}$ livello, in Italian. Available at: https://protezionecivile.regione.abruzzo.it/files/rischio\%20sismico/verificheSism/Manuale_e_sch eda_GNDT_II_livello.pdf

34) GNDT 1999. Scheda di vulnerabilità di $2^{\circ}$ livello (muratura), in Italian. Available at: https://emidius.mi.ingv.it/GNDT2/Strumenti/Schede/Schede_vulnerabilita/scheda_secondo_livell o_mur.pdf

35) Gonzalez-Drigo, R., Avila-Haro, J.A., Barbat, A.H., Pujades L.G., Vargas, Y.F., Lagomarsino, S., and Cattari, S. 2015. Modernist Unreinforced Masonry (URM) Buildings of Barcelona: Seismic Vulnerability and Risk Assessment. International Journal of Architectural Heritage, 9(3):214-230.

36) Grimaz, S. 1993. Valutazione della vulnerabilità sismica di edifici in muratura appartenenti ad aggregati strutturali sulla base di analisi a posteriori (in Italian). Ingegneria sismica, Anno X, n.3.

37) Grünthal, G., Musson, R., Schwarz, J. and Stucchi, M. 1998. European macroseismic scale. Centre Européen de Géodynamique et de Séismologie, Luxembourg; Vol. 15.

38) ISDR 2015. Hyogo Framework for Action 2005-2015: Building the Resilience of Nations and Communities to Disasters. In UN World Conference on Disaster Risk Reduction, Sendai, Japan.

39) Ismail, N., and Ingham, J.M. 2016. In-plane and out-of-plane testing of unreinforced masonry walls strengthened using polymer textile reinforced mortar. Engineering Structures, 118:167-177.

40) Jiménez, B., Pelà, L., and Hurtado, M. 2018. Building survey forms for heterogeneous urban areas in seismically hazardous zones. Application to the historical center of Valparaíso, Chile. International Journal of Architectural Heritage, present volume. 
41) King, S. 1995. Regional seismic hazard and risk analysis through geographic information systems. Doctoral Dissertation, Stanford University, CA, USA.

42) Korkmaz, K.A., Irfanoglu, A., and Kayhan, A.H. 2010. Seismic risk assessment of buildings in Izmir, Turkey. Natural Hazards, 54(1):97-119.

43) Lagomarsino, S., and Giovinazzi, S. 2006. Macroseismic and mechanical models for the vulnerability and damage assessment of current buildings. Bulletin of Earthquake Engineering, 4:415-443.

44) Lagomarsino, S., and Cattari, S. 2015. PERPETUATE guidelines for seismic performance-based assessment of cultural heritage masonry structures. Bulletin of Earthquake Engineering, 13(1):1347.

45) Lantada, N., Pujades, L.G., and Barbat, A.H. 2009. Vulnerability index and capacity spectrum based methods for urban seismic risk evaluation. A comparison. Natural Hazards, 51:501-524.

46) Lantada, N., Irizarry, J., Barbat, A.H., Goula, X., Roca, A., Susagna, T., and Pujades, L.G. (2010). Seismic hazard and risk scenarios for Barcelona, Spain, using the Risk-UE vulnerability index method. Bulletin of Earthquake Engineering, 8:201-229.

47) Lignola, G.P., Caggegi, C., Ceroni, F., De Santis, S., Krajewski, P., Lourenço, P.B., Morganti, M., Papanicolaou, C.C., Pellegrino, C., Prota, A., and Zuccarino, L. 2017. Performance assessment of basalt FRCM for retrofit applications on masonry. Composites Part B: Engineering, 128, 1-18.

48) Lynch, K. 2004. L’immagine della città. 65-102. Milano: Etaslibri.

49) Maio, R., Ferreira, T.M., Vicente, R., and Estêvão, J. 2016. Seismic vulnerability assessment of historical urban centres: Case study of the old city centre of Faro, Portugal. Journal of Risk Research, 19(5):551-580.

50) Melchers, R. E. 1999. Structural Reliability Analysis and Prediction. Hoboken: John Wiley \& Sons.

51) Minafò, G. 2015. A practical approach for the strength evaluation of RC columns reinforced with RC jackets. Engineering Structures, 85:162-169.

52) Mouroux. P., Bertrand, E., Bour, M., Le Brun, B., Depinois, S., and Masure, P. 2004. The European RISK-UE project: an advanced approach to earthquake risk scenarios. In Proceedings of the 13th World Conference on Earthquake Engineering. Vancouver, Canada, paper 3329.

53) NCSE-02 2002. Norma de Construcción Sismorresistente Española. Parte General y de Edificación. Comisión Permanente de Normas Sismorresistente, Real Decreto 997/2002 del 27 de 
septiembre de 2002, Boletín Oficial del Estado $n^{\circ}$ 244, viernes 11 de octubre de 2002. Ministerio de Fomento, 35898-35967.

54) Novelli, V.I., D’Ayala, D., Makhloufi, N., Benouar, D., and Zekagh, A. 2015. A procedure for the identification of the seismic vulnerability at territorial scale. Application to the Casbah of Algiers. Bulletin of Earthquake Engineering, 13(1):177-202.

55) Paskaleva, K. 2009. Enabling the smart city: the progress of e-city governance in Europe. International Journal of Innovation and Regional Development, 1(4):405-422.

56) Paricio Casademunt, A. 2001. Secrets d'un sistema constructiu: l’Eixample. Barcelona: Edicions UPC.

57) Pinto, P.E., Giannini, R., and Franchin, P. 2004. Seismic reliability analysis of structures. Pavia: IUSS Press.

58) Pujades L.G., Barbat A.H., González-Drigo J.R., Avila J., and Lagomarsino S. 2012. Seismic performance of a block of buildings representative of the typical construction in the Eixample district in Barcelona (Spain). Bulletin of Earthquak Engineering, 10:331-349.

59) Sarris, A., Loupasakis, C., Soupios, P., Trigkas, V., and Vallianatos, F. 2010. Earthquake vulnerability and seismic risk assessment of urban areas in high seismic regions: Application to Chania City, Crete Island, Greece. Natural Hazards, 54(2):395-412.

60) Secanell, R., Goula, X., Susagna, T., Fleta, J., and Roca, A. 2004. Seismic hazard zonation of Catalonia, Spain, integrating uncertainties. Journal of Seismology 8(1):24-40.

61) Staniscia, S., Spacone, E., and Fabietti, V. 2017. Performance-Based Urban Planning: Framework and L'Aquila Historic City Centre Case Study. International Journal of Architectural Heritage, 11(5):656-669.

62) Tilio L., Murgante B., Di Trani F., Vona M., Masi A. 2011. Resilient City and Seismic Risk: A Spatial Multicriteria Approach. In Computational Science and Its Applications - ICCSA 2011. Lecture Notes in Computer Science, 6782:410-422. Edited by Murgante B., Gervasi O., Iglesias A., Taniar D., Apduhan B.O. Berlin Heidelberg: Springer-Verlag.

63) Triantafillou, T.C. 2016. Strengthening of Existing Concrete Structures: Concepts and Structural Behavior. In Textile Fibre Composites in Civil Engineering, Edited by Triantafillou T., 303-322.

64) Triantafillou, T.C. 2016. Strengthening of Existing Masonry Structures: Concepts and Structural Behavior. In Textile Fibre Composites in Civil Engineering, Edited by Triantafillou T., 361-374. 
65) Triantafillou, T.C., Karlos, K., Kefalou, K., and Argyropoulou, E. 2017. An innovative structural and energy retrofitting system for URM walls using textile reinforced mortars combined with thermal insulation: Mechanical and fire behavior. Construction and Building Materials, 133:1-13.

66) Uva, G., Sanjust, C.A., Casolo, S., and Mezzina, M. 2016. ANTAEUS Project for the Regional Vulnerability Assessment of the Current Building Stock in Historical Centres. International Journal of Architectural Heritage 10(1):20-43.

67) Vicente R., Parodi S., Lagomarsino S., Varum H., and Mendes Silva J.A.R. 2011. Seismic vulnerability and risk assessment: case study of the historic city centre of Coimbra, Portugal. Bulletin of Earthquake Engineering 9:1067-1096. 